\title{
Models of Information Exchange for UK telehealth systems
}

\author{
O. Adeogun*, A. Tiwari, J.R. Alcock
}

School of Applied Sciences, Cranfield University,

Cranfield, Bedfordshire, MK43 OAL, UK

*Corresponding Author: Oluseun Adeogun, o.adeogun@cranfield.ac.uk;

a oluseun@hotmail.com; 01234750111 Ext 5656

Keywords: Information exchange, Model, Point-of-care device, Telehealth 


\section{Abstract}

Aim: The aim of the paper was to identify the models of information exchange for UK telehealth systems.

Methodology: Twelve telehealth offerings were evaluated and models representing the information exchange routes were constructed. Questionnaires were used to validate the diagrammatical representations of the models with a response rate of $55 \%$.

Results: The models were classified as possessing four sections: preparing for data transfer, data transfer, information generation and information transfer from health professional to patient.

In preparing for data transfer, basic data entry was automated in most systems though additional inputs (i.e. information about diet, lifestyle and medication) could be entered before the data was sent into the telehealth system.

For the data transfer aspect, results and additional inputs were sent to intermediate devices, which were connectors between point-of-care devices, patients and health professionals. Data were then forwarded to either a web portal, a remote database or a monitoring/call centre.

Information generation was either through computational methods or through the expertise of health professionals.

Information transfer to the patient occurred in four forms: email, telehealth monitor message, text message or phone call.

Conclusion: On comparing the models, three generic models were outlined. Five different forms of information exchange between users of the system were identified: 
patient-push, system-stimulation, dialogue, health professional-pull and observation. Patient-push and health professional-pull are the dominant themes from the telehealth offerings evaluated. 


\section{Introduction}

\subsection{Definitions of Telehealth}

Telehealth is defined as "the use of information, computing and telecommunications technologies to provide" health related services when health professionals and patients are separated by a distance [1]. Koch has added that telehealth developed from telemedicine but has extended to "health promotion and disease prevention" [2]. Telemedicine has several definitions: the practice of medicine between health professionals and patients when they are not in the same location [3]; the exchange of information between multiple health professionals as a means of training and education [4]; facilitating clinical consultations through an electronic medium e.g. through the telephone, videoconference and email [5]; using telecommunications technologies for exchanging health information and also the provision of services [6]. In summary, the goal of telehealth is to provide medical care at a distance in an efficient manner via a number of media.

\subsection{Benefits of telehealth for point-of-care devices}

Devices which enable testing and also aid in delivering a form of therapy near a patient are known as point-of-care (POC) devices [7]. Glucometers [8, 9] and peak flow meters [10] are examples of point-of-care testing (POCT) devices used within the home for monitoring long term conditions such as diabetes and asthma respectively. At subsequent appointments with their health professional, results recorded by patients 
can be reviewed, and patients may be informed to either maintain or alter their current lifestyle routines $[11,12]$.

Point-of-care devices are not limited to being used in a specific location as they can be used in the home of the patient, the GP surgery or in hospitals [13]. Coupling this feature with telehealth therefore extends their functionalities.

The case for telehealth being used in conjunction with point-of-care devices is based on perceived benefits such as the following:

- Helping to improve patient compliance with medication. Mao et al. described how a mobile pharmacy service system utilizing SMS was used to help improve medication compliance [14]. Text messages were sent to patients reminding them to take their medication prior to the time it was due to be taken. It demonstrated that patients found the messages helpful in complying with their medication.

- Helping to empower patients as they become more knowledgeable and confident about managing their condition. Franklin et al. described a system known as "Sweet Talk" which was designed to help young people with diabetes manage their condition through text messaging [15].Personalized messages reminding patients of their goals were sent to them based on their profiles. The patients were also encouraged to send in messages with relevant information about diabetes.

- Speeding up the rates of change of medication. Brown et al. showed that patients with diabetes may need to change their medication and the time taken 
to do this may be between $27-35$ months, however this time could be reduced through telehealth since regular updates of the patients' results could help health professionals make changes to medications quickly [16].

- Supplementing care provided to patients in between visits to health professionals. Azar and Gabbay noted this to occur when they investigated whether electronic uploading of glucose results was an advantage compared with manual methods [17]. They found that although telehealth did not make an impact on diabetes management by people with type 1 diabetes, it helped those with type 2 diabetes to manage their condition [17].

\subsection{Drivers for Telehealth}

Speedie et al. noted two assumptions of current delivery of care to patients which will be altered by telehealth [18]. They are: provision of care to patients is in a fixed "geographic" location and as "episodic" visits. The UK Department of Health (DH) also advocates that technology can be used to improve the delivery of healthcare by allowing remote patient monitoring. This allows patients to stay in their own homes rather than restricting them to a hospital setting [19]. To support this, the Department of Health is currently running a program known as 'Whole System Demonstrators' which is investigating the effect of telehealth and telecare systems on the monitoring of patients and how they may improve patient lifestyles [20]. Prior to the UK Department of Health program, several systems have emerged to deliver healthcare remotely. Some of these are being offered as pilot projects while others have been 
deployed on a larger scale. The UK was therefore selected as it provided several choices of telehealth systems that have been deployed.

\subsection{Motivation}

There is little available in the literature on different offerings of telehealth. Kruger has described three different models, "basic", "advanced" and "cloud-based" representing information flow schemes between components of "eHealth" systems [21]. eHealth systems refer to telehealth systems using the internet only as a means of exchanging information and therefore cannot be applied generically. Telehealth, however as defined in section 1.1 extends to other forms of telecommunications technology. This paper is therefore an analysis of telehealth offerings rather than eHealth offerings with the aim of identifying its overall structure and the data/information flows that are present.

\subsection{Research Questions}

This paper aimed to derive models of information exchange for telehealth offerings which are currently available.

The paper posed three research questions concerning telehealth systems.

1. What are the paths of information transfer in the telehealth offerings?

2. What types of entities form part of telehealth offerings?

3. Can a standard model of information transfer in a telehealth offering be established? 


\section{Methodology}

The criteria for selection of the data set of the paper were restricted to offerings available in the UK and those based on point-of-care devices, specifically those devices which could be used in the home.

An online search was performed through Google to identify what telehealth systems were currently available in the UK. The keywords used in the search included: point-ofcare devices, telehealth, telemedicine, eHealth, home telehealth solutions UK, telemedicine services and telehealth companies. As the paper's focus was on telehealth, telecare was excluded as a search term.

The UK Telemedicine and E-health Information Service (TEIS) provided by the University of Portsmouth [22] was also a useful resource in identifying organizations within the UK offering telehealth.

\subsection{Modelling the telehealth offerings}

Company documentation of each offering was evaluated. The sub-sections of each telehealth system were defined and the routes for the generation and exchange of information between sections of the telehealth system were identified.

Each offering, comprising the system sub-sections and the information exchange routes, was depicted diagrammatically. Formalised tools such as UML data flow diagrams or IDEFO were considered for this task, but they lacked the necessary flexibility to represent section types and information exchange. Therefore, symbols 
based on the type of entities identified were defined. This symbol set is shown in Table I.

Where the direction of information flow could be discerned this was given a direction arrow in the symbol set. In certain cases an assumed direction of information transfer is given where this could be inferred from but was not explicitly mentioned in the information available. 
Table I - Key to symbols used to draw telehealth offerings.

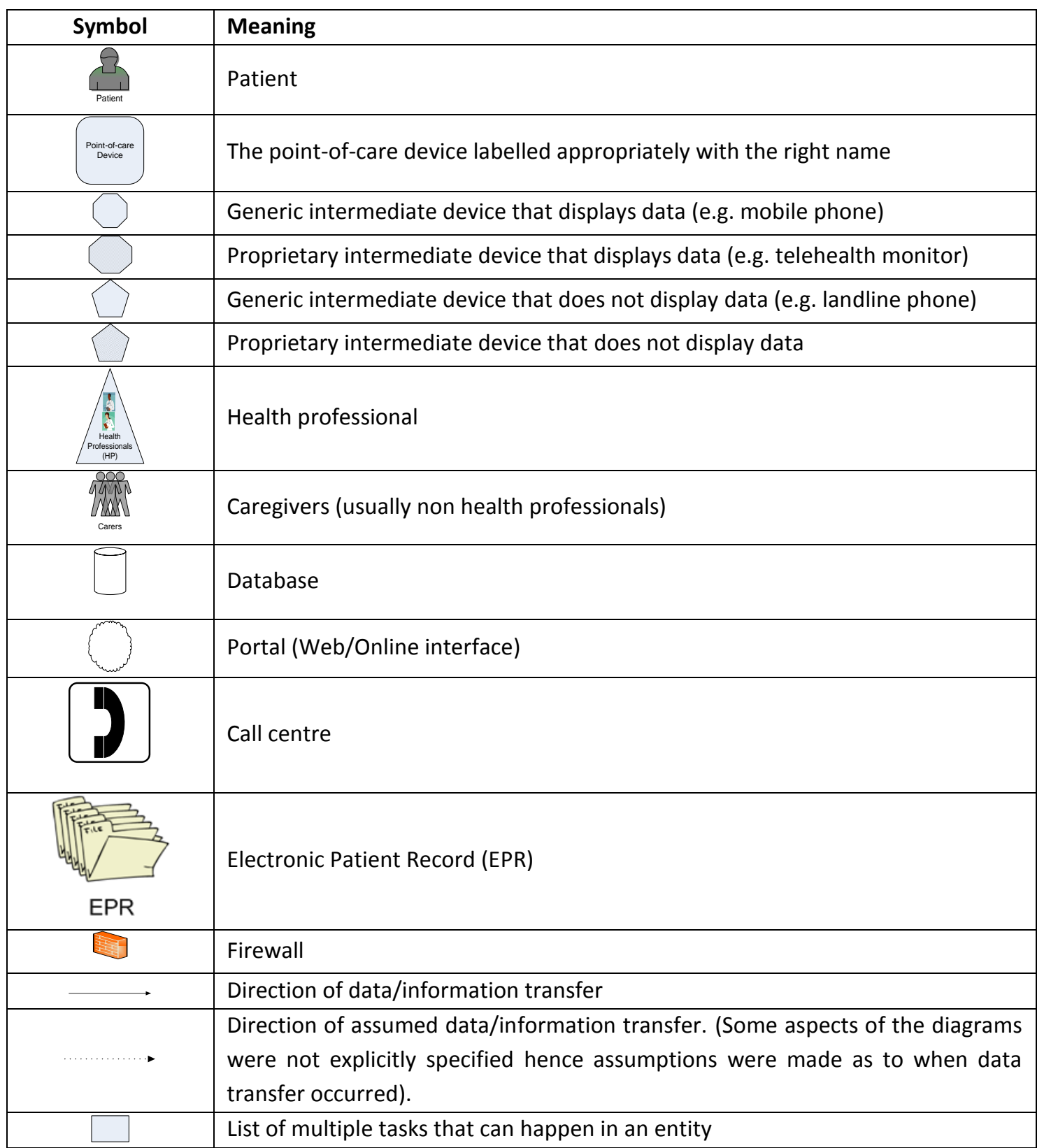

\subsection{Validation of the telehealth offerings}

To validate the diagrammatic depiction of the offerings as being accurate representations of the companies' telehealth offerings, questionnaires were sent to 
the organizations via email. The questions posed asked the organizations to make changes to the diagrams as needed. 


\section{Results}

This section provides information about the defined entities used to depict the offerings and the organizations surveyed. The detailed description of each of the 12 telehealth offerings referred to as offering $A$ to $L$ can be found in the supplementary material.

\subsection{Entities}

Eleven entities were identified as being present across the offerings: the patient, pointof-care devices, intermediate devices that had data display capabilities, such as telehealth monitors and mobile phones, intermediate devices that did not have data display capabilities, health professionals, care givers, databases, 'web portals', call centres, electronic patient records (EPRs) and firewalls.

The above entities are defined as follows:

- Patients are the primary users of the system.

- Point-of-care devices enable testing or therapy to be administered at the patient's location; examples are glucometers and blood pressure monitors.

- Intermediate devices are defined here as connectors between point-of-care devices, patients and health professionals. Some are generic devices that have been adapted to a telehealth system, for example mobile phones; others are proprietary devices.

- Health professionals are doctors or nurses. 
- Caregivers provide a form of care to the patient but are not necessarily a health professional.

- Databases are used for storing results from the devices.

- Portals are web-based interfaces available to both patients and health professionals to view current and historical results obtained from the point-ofcare devices.

- Call centres are central locations used to receive phone calls to aid in the administration of a product or service.

- EPRs are defined as electronic records of the patient's medical history usually accessible only to health professionals.

- Firewalls are part of a computer system which provide security by preventing unauthorised access and allowing authorised communications.

\subsection{Organizations evaluated}

Eleven organizations were found to offer telehealth services currently in use within the UK (AxSys Technology Ltd [23], Broomwell HealthWatch [24, 25], Docobo [26], Entra Health Systems Ltd [27] /MyGlucoHealth [28], Intel [29, 30], Philips [31], Project E-vita [32], Telehealth Solutions [33, 34], OBS Medical Ltd [35], Tunstall [36] and Tynetec [37]. Twelve offerings were identified as one organization offered two systems.

The telehealth systems were all used for monitoring one or more chronic conditions namely: asthma, chronic obstructive pulmonary disease (COPD), congestive heart 
failure (CHF), diabetes and hypertension. One offering was for managing a single condition, while eleven were for managing multiple conditions.

\subsection{Baseline Model}

A baseline model (Figure 1) for information exchange was deduced from the telehealth offerings. For readability, it is shown in this section to enable the function of each entity to be seen through each telehealth offering, however further details of how it was derived are shown in section 4.3.

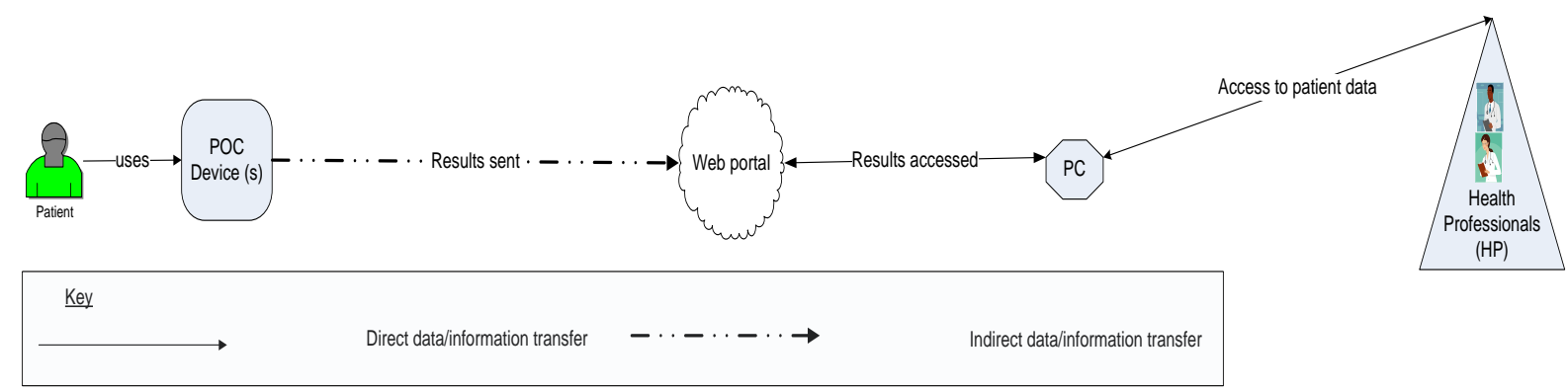

Figure 1 - The baseline model for information exchange: all systems have these functions

\subsection{Validating results}

The time period given to receive the responses back from the organizations was two months and $55 \%$ of the them (Offerings $B, D, E, H, I, L$ ) responded within this time frame. All the diagrams for which feedback was received were modified with significant changes made to offering $D$ and I. 


\subsection{Constraints by organizations when implementing telehealth offerings.}

When the organizations were asked whether they had any constraints in the design of their system, B, D and J provided information that they were not operating under explicit constraints when implementing the telehealth system.

For offering E, the constraints were small, light and simple devices suitable for use by elderly people. In addition, they had to be suitable for connecting to a telephone line. The remaining organizations did not respond or return their questionnaire.

\subsection{Standards}

Descriptions of four of the offerings stated that they used standards. Offering B had medical devices with EN60601 certification of safety and performance of the medical device [38]. Offering $\mathrm{C}$ and $\mathrm{E}$ used medical devices that were certified to ISO 13485 a standard for quality control [40]. Offering C also had ISO 9001 certification [41]. The glucometer in offering A and intermediate device in offering I carried the CE mark thus showing conformation to "essential requirements" within Europe for health, safety and environmental protection. The intermediate devices in offering B and I had FDA approval which meant that they were suitable for use in USA. (See Table VI for details). 


\section{Discussion}

Tabulated comparisons of the offerings are given tables II - VI. Table II shows the types of chronic diseases being managed by the telehealth offering. Table III represents the comparisons of the sections of the offerings prior to the transfer of data within the telehealth system. Table IV represents comparisons when the user transfers data into the telehealth system. Table $V$ shows the comparisons of the offerings based on information generation and transfer of information to the patient. Table VI compares how data is stored and accessed in the offerings.

\subsection{Comparing the telehealth offerings}

\section{Chronic diseases being monitored}

Table II shows the range of chronic diseases that could be monitored by the different telehealth offerings available. Some systems could monitor additional conditions that were not necessarily chronic and these have been represented as 'other conditions'. For two of the telehealth offerings, the conditions were not specified. 
Table II - Comparison of the information path diagrams - chronic diseases being monitored

\begin{tabular}{|c|c|c|c|c|c|c|c|c|c|c|c|c|}
\hline $\begin{array}{c}\text { Type of condition being } \\
\text { monitored }\end{array}$ & 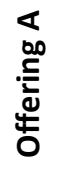 & 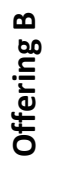 & 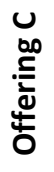 & 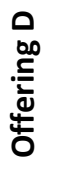 & 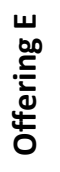 & 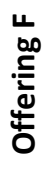 & 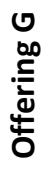 & 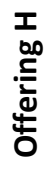 & 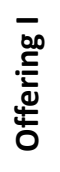 & 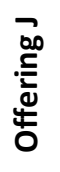 & 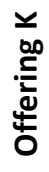 & 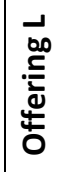 \\
\hline Diabetes & $\checkmark$ & $\checkmark$ & $\checkmark$ & & & $\checkmark$ & $\checkmark$ & $\checkmark$ & $\checkmark$ & & & $\checkmark$ \\
\hline Congestive heart failure (CHF) & & $\checkmark$ & & $\checkmark$ & $\checkmark$ & $\checkmark$ & & $\checkmark$ & & & & \\
\hline Chronic heart failure & & & & & & & $\checkmark$ & & $\checkmark$ & & & $\checkmark$ \\
\hline $\begin{array}{c}\text { Chronic obstructive pulmonary } \\
\text { disease (COPD) }\end{array}$ & & $\checkmark$ & $\checkmark$ & $\checkmark$ & $\checkmark$ & $\checkmark$ & $\checkmark$ & $\checkmark$ & $\checkmark$ & & & $\checkmark$ \\
\hline Hypertension & & $\checkmark$ & $\checkmark$ & & & $\checkmark$ & $\checkmark$ & $\checkmark$ & & & & \\
\hline Asthma & & & $\checkmark$ & & $\checkmark$ & $\checkmark$ & & & & & & \\
\hline Other conditions & & $\checkmark$ & & $\checkmark$ & $\checkmark$ & & $\checkmark$ & & & & & \\
\hline Unspecified & & & & & & & & & & $\checkmark$ & $\checkmark$ & \\
\hline
\end{tabular}

\section{Preparing for data transfer}

Table III shows that for all the telehealth offerings, the primary user of the point-ofcare device was the patient. Offering $D$ also provided a service allowing health professionals to be primary users. The testing process was initiated by the patient in nine of the systems while the intermediate device prompted patients to perform their test in three offerings $(G, H, I)$. 
Table III - Comparison of the information path diagrams - preparing for data transfer stage

\begin{tabular}{|c|c|c|c|c|c|c|c|c|c|c|c|c|c|}
\hline & & 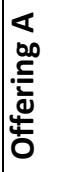 & 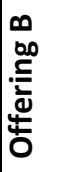 & 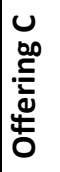 & 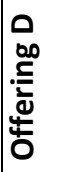 & 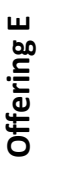 & 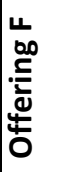 & 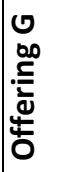 & 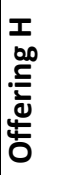 & 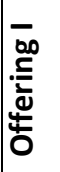 & 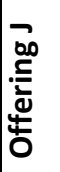 & 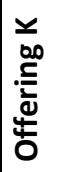 & 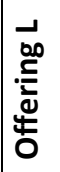 \\
\hline \multirow[t]{2}{*}{ Users } & $\begin{array}{l}\text { Primary user of } \\
\text { point-of-care } \\
\text { (POC) device is } \\
\text { patient }\end{array}$ & $\checkmark$ & $\checkmark$ & $\checkmark$ & $\checkmark$ & $\checkmark$ & $\checkmark$ & $\checkmark$ & $\checkmark$ & $\checkmark$ & $\checkmark$ & $\checkmark$ & $\checkmark$ \\
\hline & $\begin{array}{l}\text { Primary user of } \\
\text { POC device is } \\
\text { health } \\
\text { Professional (HP) }\end{array}$ & & & & $\checkmark$ & & & & & & & & \\
\hline $\begin{array}{c}\text { Testing } \\
\text { process } \\
\text { initiated: }\end{array}$ & $\begin{array}{l}\text { By patient }(\mathrm{P}) \text { or } \\
\text { by device } \\
\text { prompting } \\
\text { patient }(\mathrm{D})\end{array}$ & $\mathbf{P}$ & $\mathbf{P}$ & $\mathbf{P}$ & $\mathbf{P}$ & $\mathbf{P}$ & $\mathbf{P}$ & D & D & D & $\mathbf{P}$ & $\mathbf{P}$ & $\mathbf{P}$ \\
\hline $\begin{array}{c}\text { POC Device } \\
\text { Types }\end{array}$ & $\begin{array}{c}\text { Number of types } \\
\text { of devices } \\
\text { supported }\end{array}$ & 1 & 6 & 4 & 5 & 1 & 5 & 8 & 6 & 5 & 3 & 5 & 4 \\
\hline \multirow[t]{3}{*}{$\begin{array}{c}\text { Before } \\
\text { data } \\
\text { transfer }\end{array}$} & $\begin{array}{c}\text { Users see results } \\
\text { prior to getting } \\
\text { feedback from a } \\
\text { HP }\end{array}$ & $\checkmark$ & $\checkmark$ & $\checkmark$ & $\checkmark$ & $\checkmark$ & $\checkmark$ & $\checkmark$ & $\checkmark$ & $\checkmark$ & $\checkmark$ & $\checkmark$ & $\checkmark$ \\
\hline & $\begin{array}{c}\text { Users provide } \\
\text { additional inputs }\end{array}$ & & $\checkmark$ & $\checkmark$ & & $\checkmark$ & $\checkmark$ & $\checkmark$ & $\checkmark$ & $\checkmark$ & & $\checkmark$ & $\checkmark$ \\
\hline & $\begin{array}{l}\text { Manual (M) or } \\
\text { Automated (A) } \\
\text { data entry }\end{array}$ & A & A & $M$ & A & A & A & A & A & A & A & A & $\begin{array}{l}\mathrm{A} / \\
\mathrm{M}\end{array}$ \\
\hline
\end{tabular}

\section{Data transfer from patient to a health professional}

As shown in Table IV, the first stage of information exchange began with the transfer of data from the point-of-care device to an intermediate device. Following this, data were then transferred to either of the following locations: a web portal i.e. an online web interface: Offerings $(A, B, C, G, H, J)$; a remote database: Offerings $(E, F, I, L)$; and a monitoring/call centre: Offerings (D, K). In Offerings (E, F, I, L), data were forwarded to a web portal after being initially transferred to a remote database. 
Table IV - Comparison of the information path diagrams - data transfer from patient to health professional

\begin{tabular}{|c|c|c|c|c|c|c|c|c|c|c|c|c|c|}
\hline & & 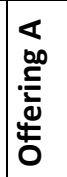 & 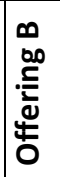 & 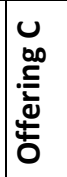 & 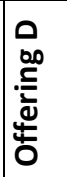 & 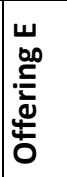 & 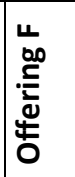 & 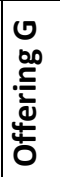 & 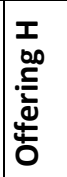 & 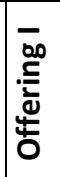 & 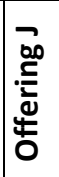 & 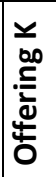 & 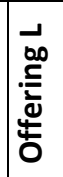 \\
\hline \multirow{2}{*}{$\begin{array}{c}\text { Results } \\
\text { transferred } \\
\text { through } \\
\text { intermediate } \\
\text { devices that } \\
\text { display data }\end{array}$} & $\begin{array}{c}\text { Proprietary } \\
\text { intermediate } \\
\text { device }\end{array}$ & & $\checkmark$ & & & $\checkmark$ & $\checkmark$ & $\checkmark$ & $\checkmark$ & $\checkmark$ & $\checkmark$ & $\checkmark$ & \\
\hline & $\begin{array}{c}\text { Adapted } \\
\text { intermediate } \\
\text { device }\end{array}$ & $\checkmark$ & $\checkmark$ & $\checkmark$ & $\checkmark$ & $\checkmark$ & & & & & & & $\checkmark$ \\
\hline \multirow{2}{*}{$\begin{array}{c}\text { Results } \\
\text { transferred } \\
\text { through } \\
\text { intermediate } \\
\text { devices that } \\
\text { do not } \\
\text { display data }\end{array}$} & $\begin{array}{c}\text { Proprietary } \\
\text { intermediate } \\
\text { device }\end{array}$ & & & & $\checkmark$ & & & & & & $\checkmark$ & & $\checkmark$ \\
\hline & $\begin{array}{c}\text { Adapted } \\
\text { intermediate } \\
\text { device }\end{array}$ & & & & $\checkmark$ & & & & & & & & \\
\hline \multirow[t]{2}{*}{$\begin{array}{l}\text { Mode of data } \\
\text { transfer: }\end{array}$} & $\begin{array}{c}\text { Through } \\
\text { wireless } \\
\text { communication }\end{array}$ & $\checkmark$ & $\checkmark$ & $\checkmark$ & $\checkmark$ & $\checkmark$ & $\checkmark$ & $\checkmark$ & $\checkmark$ & $\checkmark$ & $\checkmark$ & $\checkmark$ & $\checkmark$ \\
\hline & Through cables & $\checkmark$ & $\checkmark$ & & & & & $\checkmark$ & & & & & $\checkmark$ \\
\hline
\end{tabular}

Information generation and Information transfer from health professional to a patient

Table $\mathrm{V}$ illustrates the results discussed in the next two sections. The second stage of the information path relates to the translation of data into information of which two methods were noted in the evaluation.

\section{Information generation through computational methods}

In this scenario, data was retrieved from a server before being analysed through predefined algorithms which can be configured by health professionals. This was seen in 11 offerings $(A, B, C, E, F, G, H, I, J, K, L)$, where the results are initially analysed through software. From this, alerts can be sent to the health professionals when 
unexpected results occurred (all cases apart from offerings C \& J). In offering B, health professionals were also alerted when new data were added. Results were presented to the health professionals in a colour coded format in four offerings $(B, G, H, I)$. This enabled high priority results to be addressed quickly.

It is important to note that the colour coded signals alerting the health professionals may occasionally have false positives and false negatives, however the organizations do not provide details of their algorithms to generate the alerts therefore it was difficult to assess this.

\section{Information generation through experts}

In this scenario, no computational algorithms were used to analyse results in order to arrive at the patient diagnosis. Rather, the expertise of the health professional sufficed in making a decision which was sent back to the patient. This was demonstrated in offering D where GPs sent the patient's ECG results via the telephone and cardiology experts interpreted the ECG results and provided immediate feedback to the GP.

\section{Information transfer from health professional to a patient}

In all cases, results were accessed by health professionals via a PC. Although in offering $D$, health professionals had a more real-time contact with the patient, since the results were transmitted over the telephone line and discussed immediately. 
The traffic light colour coded system in offering B helped to identify urgent and extreme cases that may be missed if a manual method was employed. In some cases they passed on a message to the patient regarding the status of their result.

All the offerings evaluated followed the pattern of indirect data transfer in which another device other than the point-of-care device utilised transmitted the results to a portal or server. Indirect data transfer is also known as 'store and forward' and it is generally suitable for non-emergency situations [42]. 
Table V - Comparison of the information path diagrams - information generation and information

transfer to patient

\begin{tabular}{|c|c|c|c|c|c|c|c|c|c|c|c|c|c|}
\hline & & 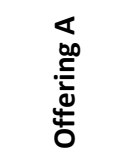 & 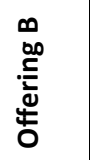 & 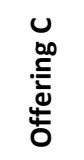 & 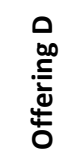 & 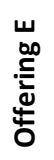 & 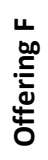 & 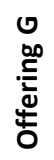 & 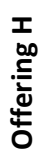 & 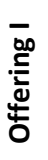 & 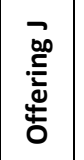 & 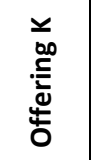 & 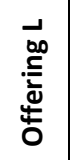 \\
\hline \multirow[t]{3}{*}{$\begin{array}{c}\text { Roles of } \\
\text { HP }\end{array}$} & $\begin{array}{l}\text { Number of } \\
\text { types of HP }\end{array}$ & 1 & 1 & 2 & 2 & 2 & 1 & 2 & 1 & 2 & 1 & 1 & 2 \\
\hline & $\begin{array}{c}\text { Description of } \\
\text { the role of } 1^{\text {st }} \\
\text { HP }\end{array}$ & & 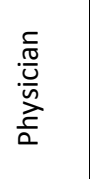 & 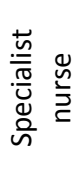 & ৩ & 仓 & 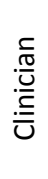 & 仓 & 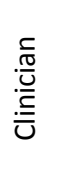 & তি & 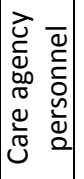 & 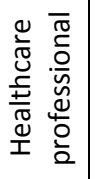 & $\stackrel{\stackrel{\aleph}{\zeta ~}}{\Sigma}$ \\
\hline & $\begin{array}{c}\text { Description of } \\
\text { the role of } 2^{\text {nd }} \\
\text { HP }\end{array}$ & & & 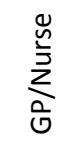 & 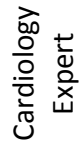 & 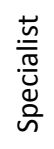 & & $\frac{\frac{\pi}{d}}{\frac{\pi}{U}}$ & & $\begin{array}{l}\frac{\pi}{\frac{n}{\pi}} \\
\frac{\pi}{\mathscr{d}} \\
\stackrel{0}{n}\end{array}$ & & & $\begin{array}{l}\frac{\pi}{\pi} \\
\frac{\pi}{\tilde{U}} \\
\frac{\pi}{n}\end{array}$ \\
\hline \multirow[t]{6}{*}{$\begin{array}{l}\text { Modes of } \\
\text { contact }\end{array}$} & $\begin{array}{l}\text { HP alerted if } \\
\text { extreme results } \\
\text { encountered }\end{array}$ & $\checkmark$ & $\checkmark$ & & $\checkmark$ & $\checkmark$ & $\checkmark$ & $\checkmark$ & $\checkmark$ & $\checkmark$ & & $\checkmark$ & $\checkmark$ \\
\hline & $\begin{array}{c}\text { HP contacts } \\
\text { patient } \\
\text { indirectly i.e. } \\
\text { through a } \\
\text { message }\end{array}$ & & $\checkmark$ & $\checkmark$ & & $\checkmark$ & $\checkmark$ & $\checkmark$ & $\checkmark$ & $\checkmark$ & & $\checkmark$ & $\checkmark$ \\
\hline & $\begin{array}{c}\text { Feedback } \\
\text { provided to } \\
\text { patient via } \\
\text { (phone call [p], } \\
\text { text [sms], } \\
\text { email [e], } \\
\text { telehealth } \\
\text { monitor } \\
\text { message [tmm]) }\end{array}$ & $\begin{array}{l}\tilde{\xi} \\
\tilde{\omega} \\
\tilde{c}\end{array}$ & $\stackrel{\xi}{\xi}$ & $\tilde{\varepsilon}$ & $\varrho$ & $\stackrel{\xi}{\xi}$ & $\stackrel{\xi}{\xi}$ & $\xi$ & $\stackrel{\xi}{\xi}$ & $\stackrel{\xi}{\xi}$ & & $\stackrel{\xi}{\xi}$ & $\stackrel{\xi}{\xi}$ \\
\hline & $\begin{array}{c}\text { HP contacts } \\
\text { patient directly }\end{array}$ & & & & $\checkmark$ & & & & & $\checkmark$ & & & $\checkmark$ \\
\hline & $\begin{array}{l}\text { Message to } \\
\text { remind patient: }\end{array}$ & 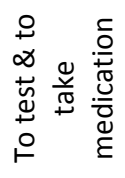 & 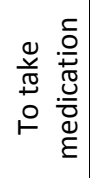 & & & & 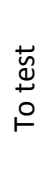 & $\begin{array}{l}\stackrel{艹}{y} \\
\stackrel{+}{\circ}\end{array}$ & $\begin{array}{l}\stackrel{艹}{y} \\
\stackrel{0}{\circ}\end{array}$ & 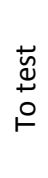 & & 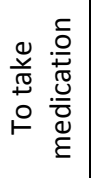 & 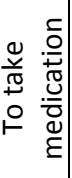 \\
\hline & $\begin{array}{c}\text { Patient can } \\
\text { contact HP } \\
\text { directly }\end{array}$ & & & & $\checkmark$ & & & & $\checkmark$ & & & & \\
\hline $\begin{array}{c}\text { User } \\
\text { Interface }\end{array}$ & $\begin{array}{c}\text { Portal } \\
\text { (Web/Online } \\
\text { interface) }\end{array}$ & $\checkmark$ & $\checkmark$ & $\checkmark$ & $\checkmark$ & $\checkmark$ & $\checkmark$ & $\checkmark$ & $\checkmark$ & $\checkmark$ & $\checkmark$ & $\checkmark$ & $\checkmark$ \\
\hline
\end{tabular}




\section{Data storage and accessibility}

The comparison of data storage and accessibility characteristics of the offerings is given in Table VI. Offerings (A, B, F, K) utilise an EPR provided by the organizations which has the medical history of the patient. The essence of storing this historical data was for reference purposes when a patient's medical history is being tracked. Offering $\mathrm{F}$ and $\mathrm{H}$ provided two databases for storing data. In offering $\mathrm{H}$, the databases were physically stored in different locations to aid data recovery during disasters and to support accessibility to data and guarantee data safety when applications fail to function thus providing extra security.

Table VI - Comparison of the information path diagrams - data storage and accessibility

\begin{tabular}{|c|c|c|c|c|c|c|c|c|c|c|c|c|c|}
\hline & & 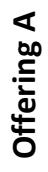 & 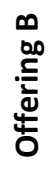 & 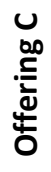 & 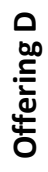 & 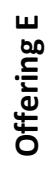 & 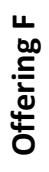 & 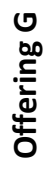 & 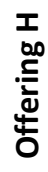 & 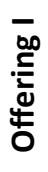 & 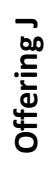 & 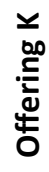 & 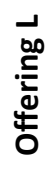 \\
\hline \multirow[t]{2}{*}{ Data Storage } & Data repository & & & & & $\checkmark$ & $\checkmark$ & & $\checkmark$ & $\checkmark$ & & & $\checkmark$ \\
\hline & $\begin{array}{c}\text { Electronic } \\
\text { Patient/Medical } \\
\text { Record }\end{array}$ & $\checkmark$ & $\checkmark$ & & & & $\checkmark$ & & & & & $\checkmark$ & \\
\hline \multirow[t]{3}{*}{$\begin{array}{c}\text { Accessibility } \\
\text { to data }\end{array}$} & $\begin{array}{l}\text { Secured access } \\
\text { to data by HP }\end{array}$ & & & $\checkmark$ & & & $\checkmark$ & $\checkmark$ & $\checkmark$ & $\checkmark$ & & & $\checkmark$ \\
\hline & $\begin{array}{c}\text { Patients can } \\
\text { access stored } \\
\text { data }\end{array}$ & $\checkmark$ & & $\checkmark$ & & $\checkmark$ & $\checkmark$ & & $\checkmark$ & $\checkmark$ & & & $\checkmark$ \\
\hline & $\begin{array}{c}\text { Caregivers can } \\
\text { access patient } \\
\text { data }\end{array}$ & $\checkmark$ & & & & & $\checkmark$ & & $\checkmark$ & & & $\checkmark$ & \\
\hline \multirow[t]{2}{*}{ Other } & Firewall & & & & & & $\checkmark$ & & & & & & \\
\hline & Uses standards & & $\checkmark$ & $\checkmark$ & & $\checkmark$ & & & & $\checkmark$ & & & \\
\hline
\end{tabular}




\subsection{Features of baseline, dominant and fully-featured models}

\section{Baseline model}

The baseline model (Figure 1) shows that five entities were common to all the offerings: the patient, point-of-care device, web portal, PC and health professional. In the baseline model, patients use a point-of-care device to generate results; the results are sent to a web portal, where they were accessed through a PC (an intermediate device) by the health professional.

\section{Dominant model}

The dominant model (Figure 2) represents the entities that were present in more than six of the offerings. In addition to the entities found in the baseline model, the dominant model included additional intermediate devices and remote databases. Results from point-of-care devices are sent via an intermediate device to either a remote database, before being accessible through a web portal, or directly to the web portal. 


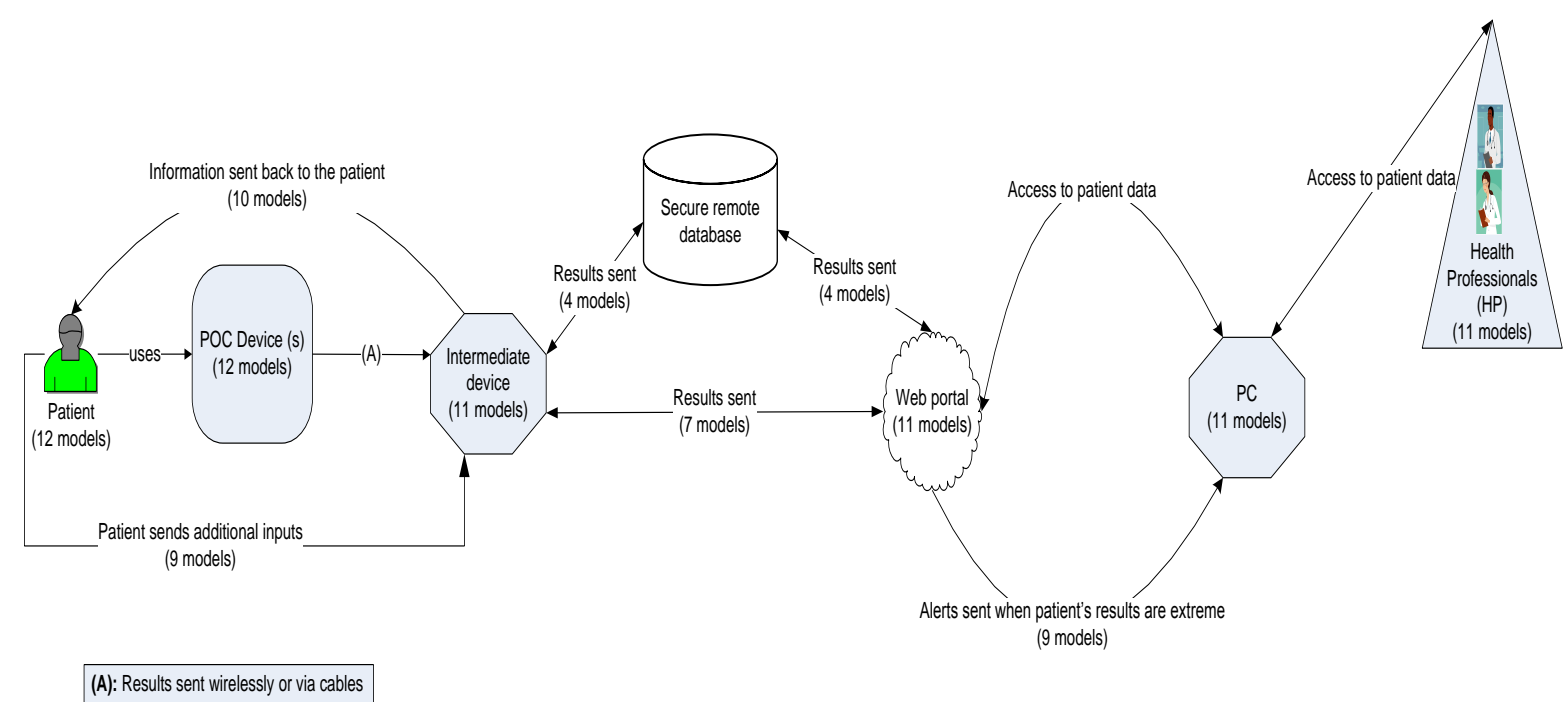

Figure 2 - The dominant model showing the entities that appear in more than 6 of the offerings

\section{Fully-featured model}

The "fully-featured" model representing all the defined entities along with their functionalities observed from all the offerings is shown in Figure 3 . Each of the 12 telehealth offerings exhibited useful features that would aid information exchange, although as expected, they were not all present in each offering, hence this fullyfeatured hypothetical model shows the complexity of the possible capabilities. The main differences between this and the baseline model are:

- Patients were reminded to either carry out their test or to take their medication.

- The intermediate device could initiate the testing process thus helping the patient to comply with regular monitoring.

- Results from point-of-care devices and responses to questionnaires (data) were sent wirelessly or via cables to the intermediate device. 
- A telephone link was added to enable the patient to speak to the health professional to aid in answering queries during the testing process.

- Patients could access their results through the web portal and also through the intermediate device.

- Results and data were encrypted before being transferred from the intermediate device that displays data to a database.

- For an intermediate device that does not display data, results were sent via a landline telephone to a call centre to be interpreted by health professionals. The interpreted information was transferred to a remote database to be stored.

- For data sent to a call centre, interpreted results were communicated to the patients through a landline telephone.

- Results and data were sent through a firewall and stored further in another remote database to increase security.

- Results and data were accessible to health professionals through a web portal via a PC.

- Health professionals could: create triggers on the patients' records; set up personalised schedules for the patients; review and analyze patients' results; and provide suggestions to patients on how to improve their results. They have additional privileges which allow them to filter the patient's result based on its priority level.

- Alerts were sent to health professionals via mobile phones or PCs when patient's results were unusual. 
- Specialists were available in the system so that they could be consulted by general practitioners to exchange information about the patient.

- An EPR was added to allow health professionals to update the patient's records.

- Caregivers were integrated into the system to help track the patient's condition and provide additional support to patients to enable compliance to routine.

From the above it can be seen that the main difference between fully-featured, dominant and baseline systems is the number of service elements for patients and health professionals that the fully-featured model adds to the system. It seems likely that telehealth providers can and will seek to differentiate themselves from competitors via such service provision. 


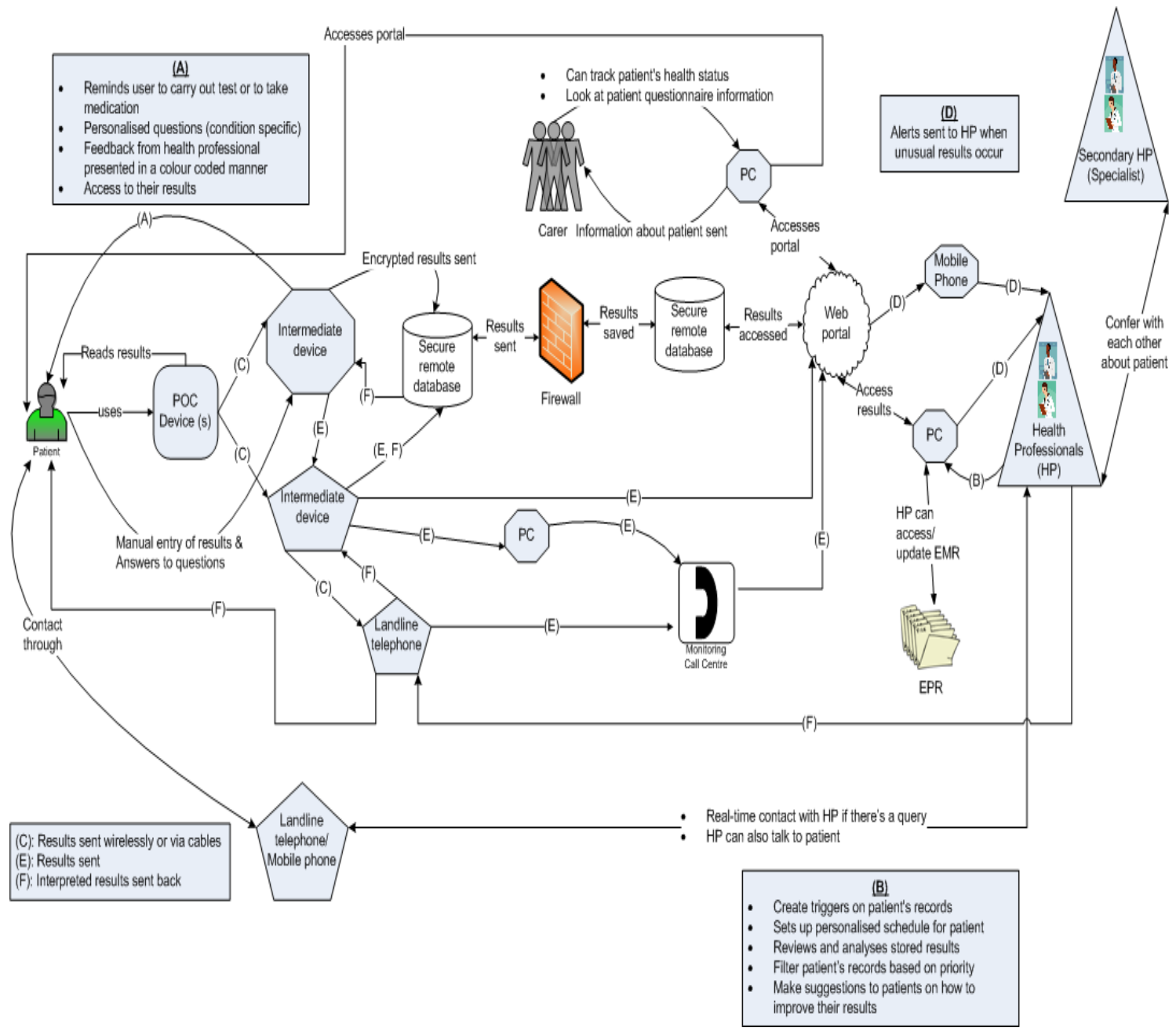

Figure 3 - A model comprising functionalities observed in all the offerings for information exchange

\section{Forms of information exchange in telehealth systems}

From this evaluation, different ways of information exchange between users of the system have been identified. They are listed in the order that information flows through:

- Patient-push: The testing process was initiated by patients, who send their test results to health professionals. Examples of this are seen in all offerings apart from $(G, H, I)$ and in the baseline, dominant and fully-featured model. 
- System-stimulation: Patients are prompted to carry out their test or take their medication through reminders. Examples of this are seen in offerings (B, F, G, $H, I, K, L)$ and in the fully-featured model.

- Dialogue: Patients and health professionals have a live dialogue either on the phone or through video conferencing to discuss results and progress of patients. Examples of this are in offerings $(D, I, H)$ and in the fully-featured model.

- Health professional-pull: Health professionals set up alerts to be informed when patients' results arrive each time or when patients' results are outside specified limits. Examples of this are seen in all the offerings apart from (C \& J) and in the dominant and fully-featured model.

- Observation: Caregivers can access information about the patient thus checking their compliance with monitoring and encouraging the patient. Examples of this are seen in offerings $(A, F, H, K)$ and in the fully-featured model.

Patient-push and health professional-pull are the leading themes from these approaches.

\section{Strengths and Weaknesses of the study}

The strengths of the study are: Providing an overall structure of telehealth offerings for managing chronic diseases by showing the entities used. Highlighting the commonality in the characteristics of telehealth offerings. It has shown three generic models of 
telehealth offerings of which the level of complexity is based on the requirements of the telehealth system.

The weaknesses of the study are: The effectiveness of such telehealth offerings has not been evaluated. The telehealth models refer to the management of chronic diseases and may not be applicable to other areas of healthcare without further work.

\section{Conclusion}

The paper presented models of information exchange in the UK telehealth industry with specific focus on telehealth offerings containing point-of-care devices.

The models were classified as possessing four sections: preparing for data transfer, data transfer, information generation and information transfer from health professional to patient.

In preparing for data transfer stage, the testing process was initiated by the patient in most systems. Most of the systems also provided automated data entry. Additional inputs, apart from the result, could be entered in most systems before the data was sent into the telehealth system.

For the data transfer stage, results and additional inputs were sent to an intermediate device, which were connectors between point-of-care devices, patients and health professionals. Data were then forwarded to either a web portal, a remote database or a monitoring/call centre.

The information generation stage took two forms: (i) information through computational methods where data was analysed through predefined algorithms and 
alerts were triggered when unusual results occurred; (ii) information through the expertise of health professionals. GPs could confer with specialists to discuss the patient's health and progress. Information transfer to the patient occurred in four forms: email, telehealth monitor message, text message or phone call. Health professionals were alerted when unusual results were recorded by patients. Reminders were sent to patients in some offerings to either carry out their test or to take their medication.

A further aspect for the offerings included data storage and accessibility. Databases were explicitly identified in five of the offerings and four of the offerings also used Electronic Patient Records (EPRs). Data were encrypted in some cases to provide additional security before it was stored.

Five different forms of information exchange between users of the system have been identified: patient push, system-stimulation, dialogue, health professional-pull and observation. Patient-push and health professional-pull are the dominant themes from the telehealth offerings evaluated.

On comparing the offerings, a baseline model was outlined comprising five of the eleven defined entities. The main difference between the 'fully-featured' and baseline model is the addition of numerous service elements to the system, for both patients and health professionals. It seems likely that telehealth providers can and will seek to differentiate themselves from competitors via such service provision. 


\section{References}

1. Fitzmaurice JM. Telehealth research and evaluation: implications for decision makers. Medical Technology Symposium, 1998. Proceedings. Pacific, August 17August 20, pp. 344.

2. Koch S. Home telehealth-Current state and future trends. International Journal of Medical Informatics 2006, vol. 75, no. 8, pp. 565-576.

3. Merriam-Webster.com [Internet]. Definition of telemedicine. c2010 [cited 2010 November 16]. Available from: http://www.merriam$\underline{\text { webster.com/dictionary/telemedicine }}$

4. American Telemedicine Association (ATA) [Internet]. Telemedicine Defined. c2010 [cited 2010 November 16]. Available from:

http://www.americantelemed.org/i4a/pages/index.cfm?pageid=3333

5. Wyatt JC and Liu JLY. Basic concepts in medical informatics. Journal of Epidemiology and Community Health 2002, vol. 56, no. 11, pp. 808-812.

6. Reid J. A Telemedicine Primer: Understanding the issues (Billings, MT: Innovative Medical Communications, 1996)

7. MeSH [Internet]. Definition of Point-of-care systems. c2010 [cited 2010 November 16]. Available from:

http://www.ncbi.nlm.nih.gov/sites/entrez?Db=mesh\&Cmd=ShowDetailView\&Term $\underline{\text { ToSearch }=68019095 \& \text { ordinalpos }=6 \& \text { itool=EntrezSystem2.PEntrez.Mesh.Mesh Res }}$ ultsPanel.Mesh RVFull 
8. Benjamin EM. Self-Monitoring of Blood Glucose: The Basics. Clinical Diabetes 2002, vol. 20 , no. 1 , pp. $45-47$.

9. Apostolopoulos A, Apostolopoulou D and Tsoubeli A. Application of health informatics in the education of diabetic patients for the improvement of selfmanagement and reporting to specialists. Journal on Information Technology in Healthcare 2007, vol. 5, no. 6, pp. 379-386.

10. PDS/Ferraris Respiratory Report. Home Electronic Asthma Monitoring. c2004 [cited 2010 November 16]. Available from:

http://www.touchbriefings.com/download.cfm?fileID=2754

11. NHS Choices. Treating Asthma. c2010 [updated 2010 August 20; cited 2010 November 16]. Available from:

http://www.nhs.uk/Conditions/Asthma/Pages/Treatment.aspx

12. NHS Choices. Treating type 2 diabetes. c2010 [updated 2010 August 17; cited 2010 November 16]. Available from: http://www.nhs.uk/Conditions/Diabetestype2/Pages/Treatment.aspx

13. Price CP and Kricka LJ. Edited on behalf of the National Institute of Biomedical Imaging and Bioengineering/National Heart, Lung, and Blood Institute/National Science Foundation Workshop Faculty. Improving Healthcare Accessibility through Point-of-Care Technologies. Clinical Chemistry 2007, vol. 53, no. 9, pp. 1665-1675.

14. Mao $\mathrm{Y}$, Zhang $\mathrm{Y}$ and Zhai S. Mobile phone text messaging for pharmaceutical care in a hospital in China, Journal of telemedicine and telecare 2008, vol. 14, no. 8, pp. 410-414. 
15. Franklin VL, Greene A, Waller A, Greene SA and Pagliari C. Patients' Engagement With "Sweet Talk" - A Text Messaging Support System for Young People With Diabetes, Journal of Medical Internet Research 2008, vol. 10, no. 2.

16. Brown JB, Nichols GA and Perry A. The burden of treatment failure in type 2 diabetes, Diabetes care 2004, vol. 27, no. 7, pp. 1535-1540.

17. Azar M and Gabbay R. Web-based management of diabetes through glucose uploads: Has the time come for telemedicine?, Diabetes Research and Clinical Practice 2009, vol. 83, no. 1, pp. 9-17.

18. Speedie SM, Ferguson AS, Sanders J and Doarn CR. Telehealth: The promise of new care delivery models. Telemedicine and e-Health 2008, vol. 14, no. 9, pp. 964-967.

19. Department of Health, Professor the Lord Darzi of Denham KBE, High quality care for all: NHS Next Stage Review final report 30-6-2008, pp. 28-29.

20. The King's Fund. WSD Action Network. c2010 [cited 2010 November 16]. Available from: http://www.wsdactionnetwork.org.uk/

21. Kruger P. Will Microsoft and Google Take Mobile Health into the Clouds? c2009 [updated 2009 May 21; cited 2010 November 16]. Available from: http://www.themobilehealthcrowd.com/?q=node/287

22. University of Portsmouth, TEIS - UK Telemedicine and E-health Information Service, Companies. c1998-2004 [cited 2010 November 16]. Available from: http://www.teis.port.ac.uk/jsp/search/organisations.jsp?field=companies\&sortby= alpha

23. AxSys Technology Ltd. What is Excelicare? c2010 [cited 2010 November 16]. Available from: http://www.axsys.co.uk/index.htm 
24. Broomwell HealthWatch. Broomwell HealthWatch Telemedical Monitoring Services. c2010 [cited 2010 November 16]. Available from: http://www.broomwellhealthwatch.com/index.php

25. Broomwell HealthWatch. What others say about us - What telemedicine means to home users (Video). c2010 [cited 2010 November 16]. Available from: http://www.broomwellhealthwatch.com/index.php?idy=161

26. Docobo. Docobo ${ }^{\circledR}$ towards a better quality of life ${ }^{T M}$. c2008 [cited 2010 November 19]. Available from: http://www.docobo.co.uk/Default.aspx

27. Entra Health Systems. Entra Health Systems. c2009 [cited 2010 November 19]. Available from: http://www.entrahealthsystems.com/

28. MyGlucoHealth. Smarter Diabetes Management for a Digital Lifestyle. c2010 [cited 2010 November 19]. Available from: http://www.myglucohealth.net/index.html 29. Intel. Intel Health Guide Overview. c2010 [cited 2010 November 19]. Available from:

http://www.intel.com/corporate/healthcare/emea/eng/healthguide/index.htm 30. Intel. Intel Health Guide Product Brief. c2009 [cited 2010 November 19]. Available from:

http://www.intel.com/corporate/healthcare/emea/eng/healthguide/pdfs/Health Guide Product Brief.pdf

31. Philips. Telehealth Solutions. c2004-2010 [cited 2010 November 19]. Available from:

http://www.healthcare.philips.com/main/products/telehealth/Products/telehealth solutions.wpd 
32. Project E-vita. Telehealth monitoring of patients in their own home. c2002-2009 [cited 2010 November 19]. Available from:

http://www.projectevita.com/products/telehealth.aspx

33. Telehealth Solutions. Welcome to Telehealth Solutions. c2010 [cited 2010 November 19]. Available from: http://www.telehealthsolutions.co.uk/

34. Telehealth Solutions. Home Pod - What it does. c2010 [cited 2010 November 19]. Available from: http://www.telehealthsolutions.co.uk/products/home-pod/

35. OBS Medical Ltd. Telehealth - T+ Medical. c2010 [cited 2010 November 19]. Available from: http://www.obsmedical.com/products

36. Tunstall. Telehealth solutions. c2010 [cited 2010 November 19]. Available from: http://www.tunstall.co.uk/Products.aspx?PagelD=19

37. Tynetec. Telehealth products. c2010 [cited 2010 November 19]. Available from: http://www.tynetec.co.uk/page/products

38. British Standards Online. BS EN 60601-1:2006 Medical electrical equipment. General requirements for basic safety and essential performance. c2010 [updated 2006 November 30; cited 2010 November 19]. Available from: https://bsol.bsigroup.com/en/My-BSI/My-Subscriptions/BSOL/Search/SearchResults/?src=s\&s=c\&snc=Y\&bwc=F\&q=BS\%20EN\%2060601-1:2006

39. FDA (Food and Drug Administration). 510(k) Clearances. c2010 [updated 2009 June 18; cited 2010 November 19]. Available from:

http://www.fda.gov/medicaldevices/productsandmedicalprocedures/deviceapprov alsandclearances/510kclearances/default.htm 
40. British Standards Online. BS EN ISO 13485:2003 Medical devices. Quality management systems. Requirements for regulatory purposes.

41. British Standards Online. BS EN ISO 9001:2008 Quality management systems. Requirements.

42. Myers MR. Telemedicine: an emerging health care technology. The health care manager 2003, vol. 22, no. 3, pp. 219-223. 


\section{Figure Legends}

Figure 1 - The baseline model for information exchange: all systems have these functions

Figure 2 - The dominant model showing the entities that appear in more than 6 of the offerings

Figure 3 - A model comprising functionalities observed in all the offerings for information exchange 


\section{Table Legends}

Table I - Key to symbols used to draw telehealth offerings.

Table II - Comparison of the information path diagrams - chronic diseases being monitored

Table III - Comparison of the information path diagrams - preparing for data transfer stage

Table IV - Comparison of the information path diagrams - data transfer from patient to health professional

Table V - Comparison of the information path diagrams - information generation and information transfer to patient

Table VI - Comparison of the information path diagrams - data storage and accessibility 


\section{Supplementary material showing the details of each telehealth offering}

\subsection{Offering A}

Offering A (Figure 1) represents a system developed for managing diabetes.

The process is initiated by the patient who carries out a blood test using a glucometer developed by the company. The glucometer has both USB and Bluetooth capabilities thus allowing results to be transferred to a PC or wirelessly to a mobile phone before being forwarded to a web portal. After results arrive at a portal, real-time access to them is available via a PC to patients, health professionals and caregivers. Alerts are sent to health professionals notifying them of unexpected results. Health professionals are also able to update the patient's EPR. Patients are able to monitor their results alongside other information which health professionals provided. Patients can send messages to their health professional or "schedule" appointments via the portal. 
Patients can access portal to:

- have real-time access to view results and how it has been analysed

- View online information and other tools

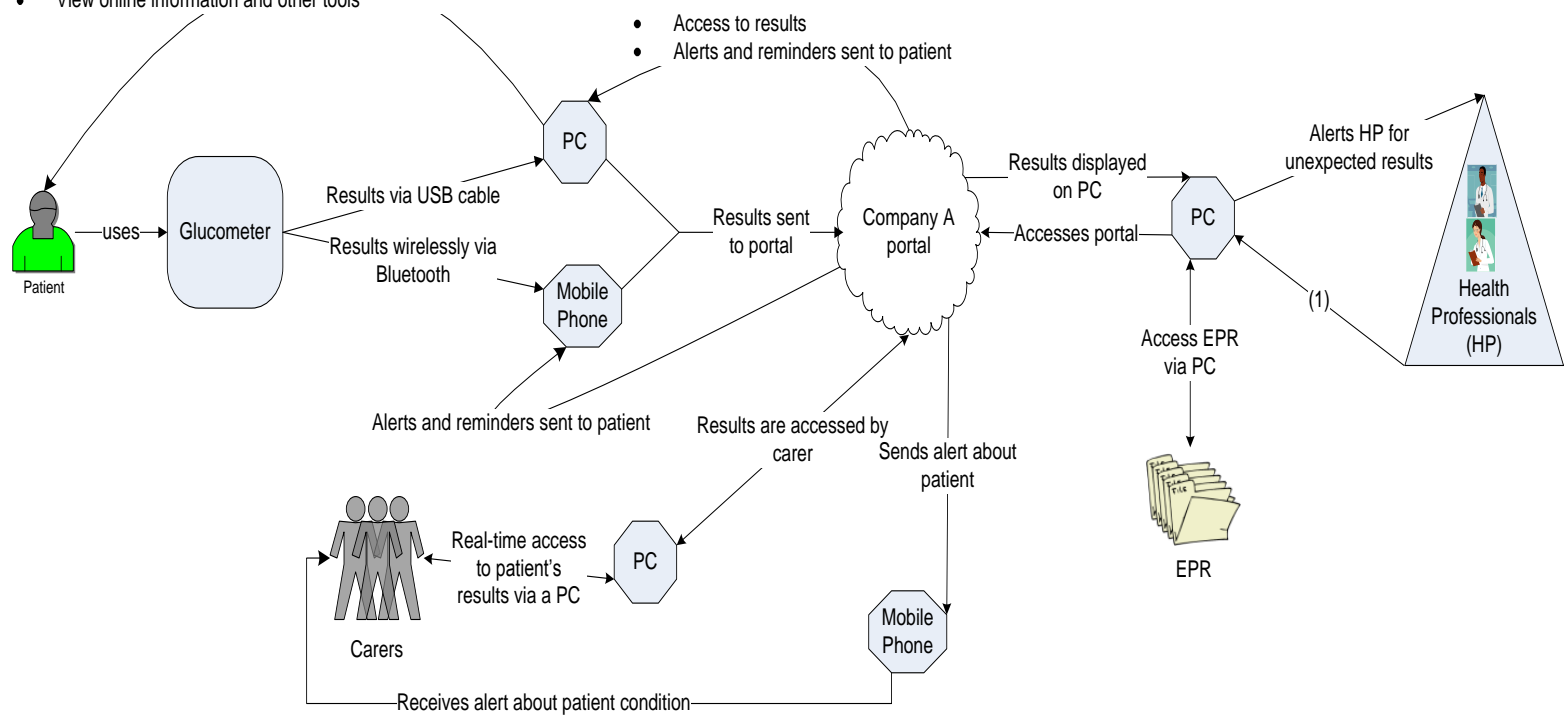

- Real-time access to patient's results

- Analyses patient's results

- Can see an overview of the patient results

- Can alter patient's medication

- Updates patient EPR

Figure 1 - Offering A representing a telehealth system for diabetes management

\subsection{Offering B}

Offering B (Figure 2) represents a system for monitoring chronic conditions such as diabetes, CHF, COPD and hypertension/high blood pressure. The system provides the capability of using six types of point-of-care devices.

The process is initiated by the patient who can use any of the following point-of-care devices: blood pressure (BP) monitor, weighing scale, coagulation meter (which measures the clotting ability of the blood), pulse oximeter, ECG (electrocardiogram) monitor and glucometer.

After testing, results are sent to four different types of intermediate devices, one generic type and three proprietary types. The generic type is a mobile phone or BlackBerry which is 
linked to point-of-care devices through Bluetooth. Of the three proprietary types, two of them are supplied by the same manufacturer Type $1 \mathrm{~A}$ and $1 \mathrm{~B}$. Type $1 \mathrm{~A}$ of the telehealth monitors transmits data through a telephone landline, while Type 1B transmits data through a GSM (Global System for Mobile Connections) mobile network. The third proprietary device is known as Type 2 and is linked for data transmission from the POC devices through a telephone landline or via Wi-Fi.

The connection types to download results from point-of-care devices include Bluetooth, infrared or an RS232 port. After passing through the intermediate devices, results are transferred securely via web services before being added to the EPR which is programmed to send alerts to health professionals based on predefined triggers. Health professionals are alerted either via a PC (email) or a mobile phone (SMS). The telehealth monitors can be equipped with scripts, which ask patients questions regarding their condition and also reminds them of medications to take.

All the types of telehealth monitors used have EU Medical Device Directive EN60601 certification [38]. In addition, the telehealth monitors (type $1 \mathrm{~A}$ and $1 \mathrm{~B}$ ) also had US Food and Drug Administration (FDA) approval 510(k) [39] while the FDA approval was still pending for telehealth monitor (type 2). 


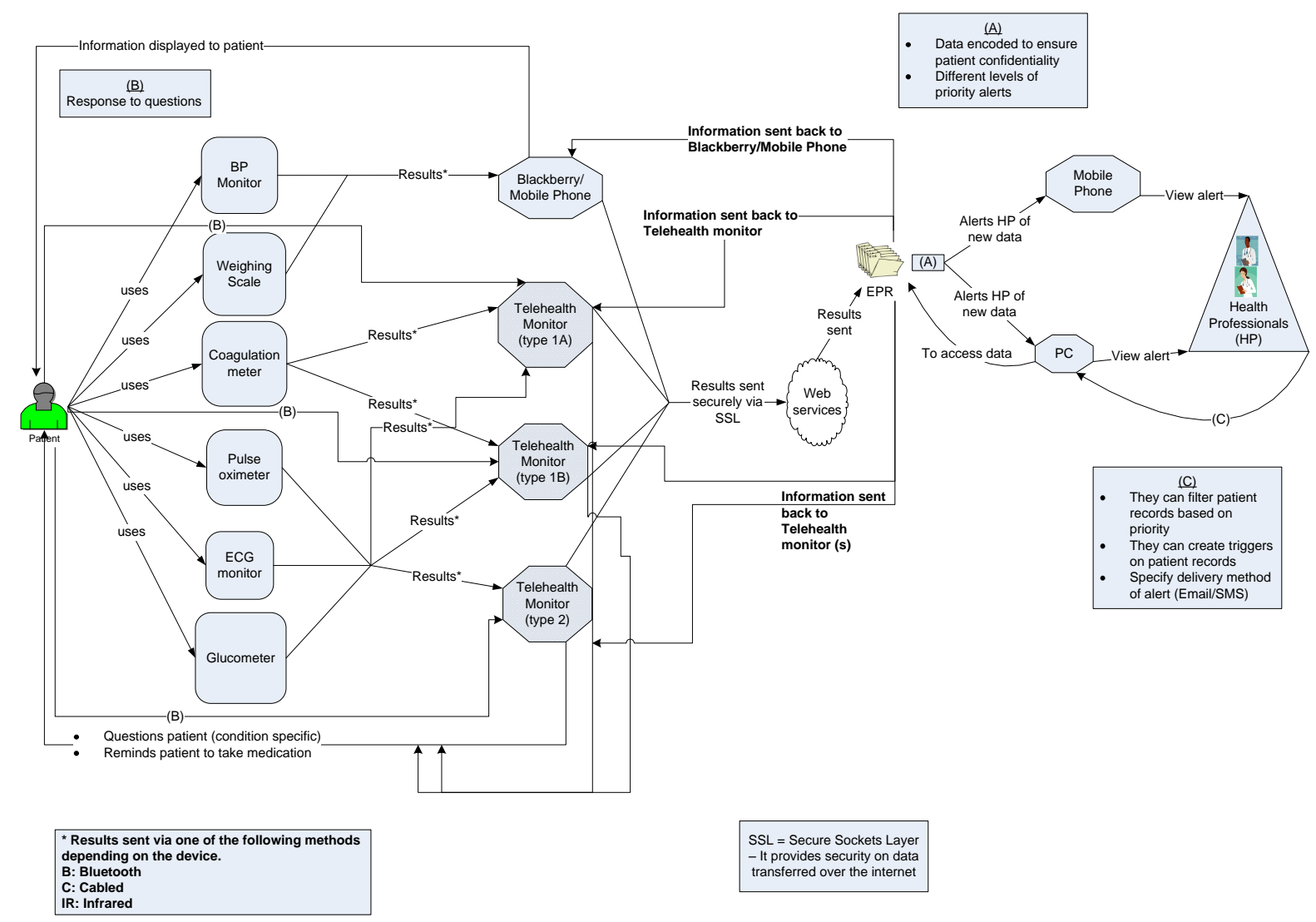

Figure 2 - Offering B representing a telehealth system for monitoring several chronic conditions

\subsection{Offering C}

Offering C (Figure 3) represents a system comprising health management tools for four different conditions, namely diabetes, high blood pressure, asthma and COPD. The following point-of-care devices can be used in the system: glucometer, BP monitor, peak flow meter and pulse oximeter.

The process begins with patients carrying out their test and manually entering results from their point-of-care device into a mobile phone preinstalled with the unique software for this task. Other parameters required to accompany the results are information relating to diet or medication and these are displayed on the mobile phone. Data are transmitted to a secure web page which is accessible to health professionals (specialist nurses and GPs). They 
review and analyse the data before its interpretation is sent back to the patient via their phone. The results on the phone are colour coded to ease interpretation of the information. The web page is also available to patients. The products used in offering $\mathrm{C}$ were certified to the following standards, ISO 13485 [40] and ISO 9001 [41].

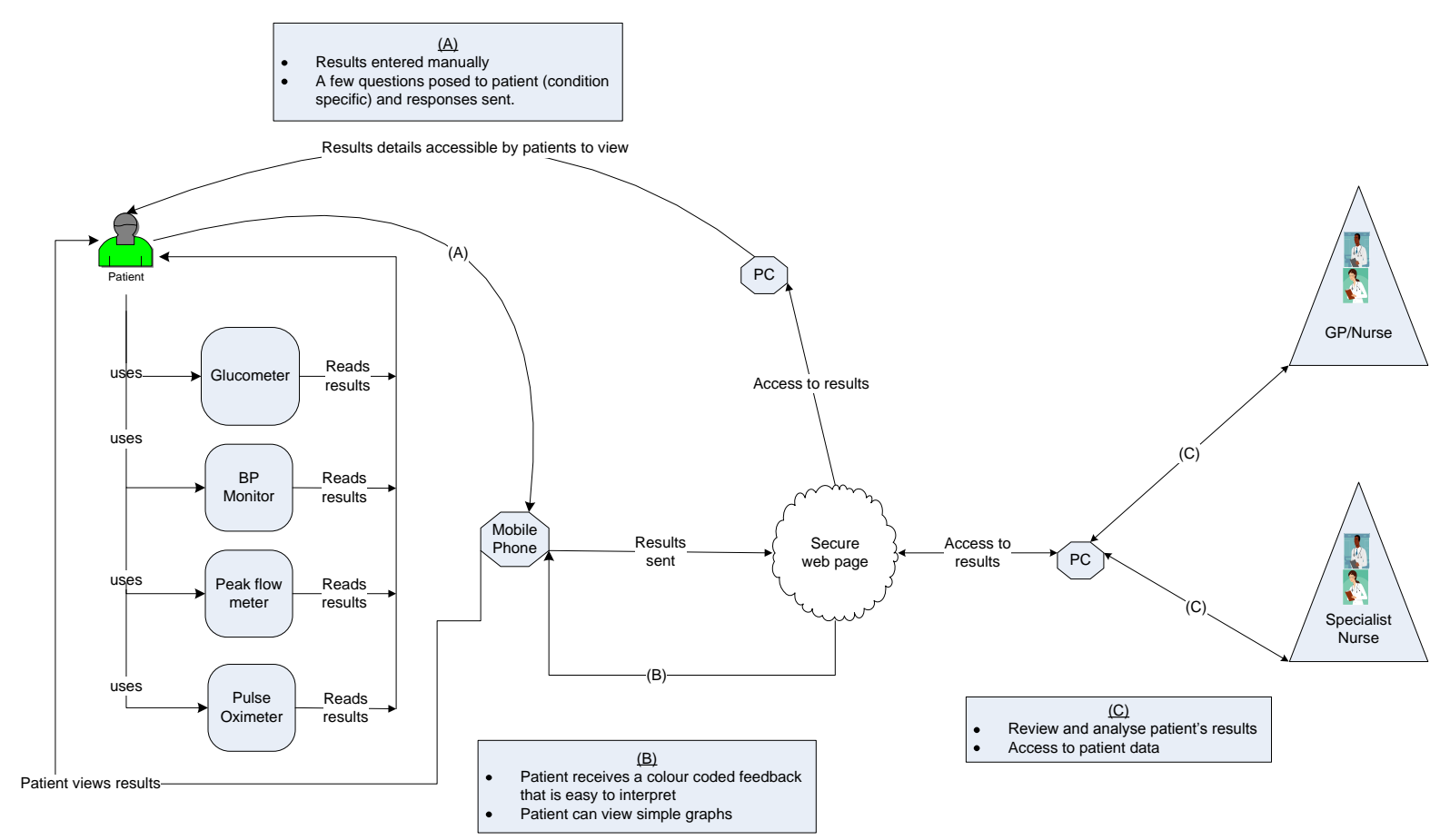

Figure 3 - Offering $\mathrm{C}$ representing a telehealth system for monitoring several chronic conditions

\subsection{Offering D}

Offering D (Figure 4) represents a system providing a remote monitoring service for patients with cardiac and respiratory conditions such as CHF, COPD and other chronic respiratory diseases. The offering consists of three sub-sections classified based on the physical location of the entities. 
Section 1 describes the service provided to patients when they are at home. The process is initiated by the patient, who can use five different types of point-of-care devices: 12 lead personal ECG monitor, weighing scale, BP monitor, all-in-one monitor (which measured pulse, blood pressure, breathing rate, temperature, heart rate, heart rhythm, ECG and blood oxygen level), and a "MiniClinic" (which helps to detect irregular/abnormal heartbeat). Results from all the devices apart from the personal ECG monitor are sent via a gateway, an intermediate device that transfers results via a telephone line to the monitoring call centre. The monitoring call centre is staffed by dedicated experts (cardiac nurses, cardiology registrars) who evaluate the results and provide its interpretation via the phone to the patient.

Section 2 describes how patients can transmit their results to the monitoring call centre if they are not at home. Only results from the "MiniClinic" can be transferred because it has storage facilities for five readings thus allowing data to be transferred via a USB MiniGate connected to a PC.

Section 3 describes the service provided to GPs who use the professional version of the ECG device. The process here is initiated by the GP carrying out the test on the patient. The device then transmits data through a landline telephone to the monitoring call centre, where experts evaluate the results and provide an initial explanation verbally. A detailed report is sent later by email or fax to the GP. 


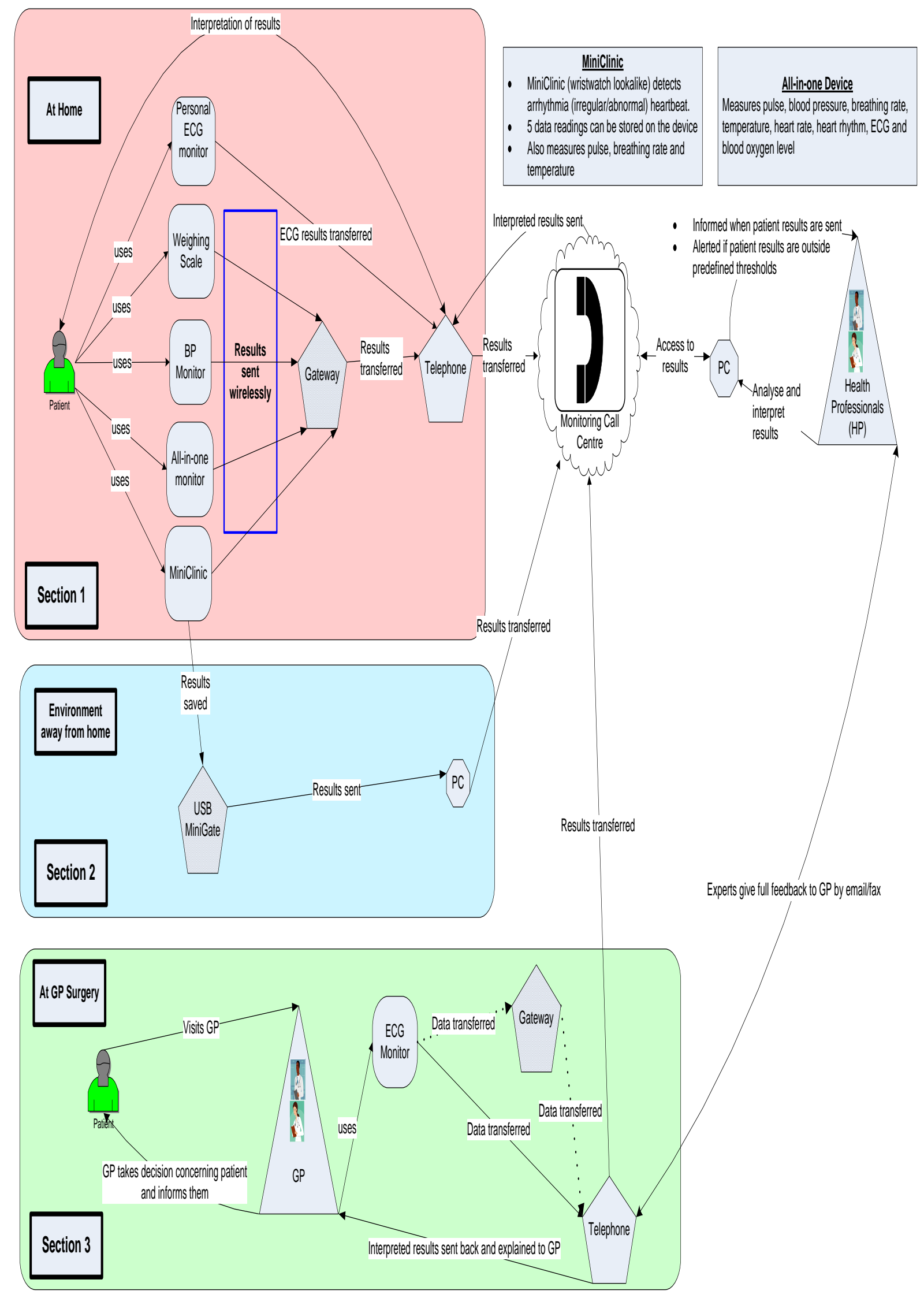

Figure 4 - Offering D representing a telehealth system for monitoring cardiac and respiratory conditions 


\subsection{Offering E}

Offering E (Figure 5) represents a telehealth system for managing and preventing long term conditions such as CHF, COPD and asthma.

The process begins with the patient using a vital signs monitor. The results are entered into any of the following three intermediate devices: PC, personal telehealth hub (similar to a personal digital assistant) or mobile phone. The personal telehealth hub is linked to the server through a telephone line. It has the capability to be personalised for each condition that is being monitored by asking the patient symptomatic questions. It also retrieves messages sent by the health professional. The results are transferred into a secure server which is accessible through a web browser to health professionals who analyse results and monitor trends before sending a message to the patient via the personal telehealth hub. Patients have access to the results. Alerts are sent to health professionals if the patient's results are unusual. This is either through an email or via SMS. GPs (primary) and specialists (secondary) health professionals can consult each other through the telehealth system to discuss the patient's progress. 


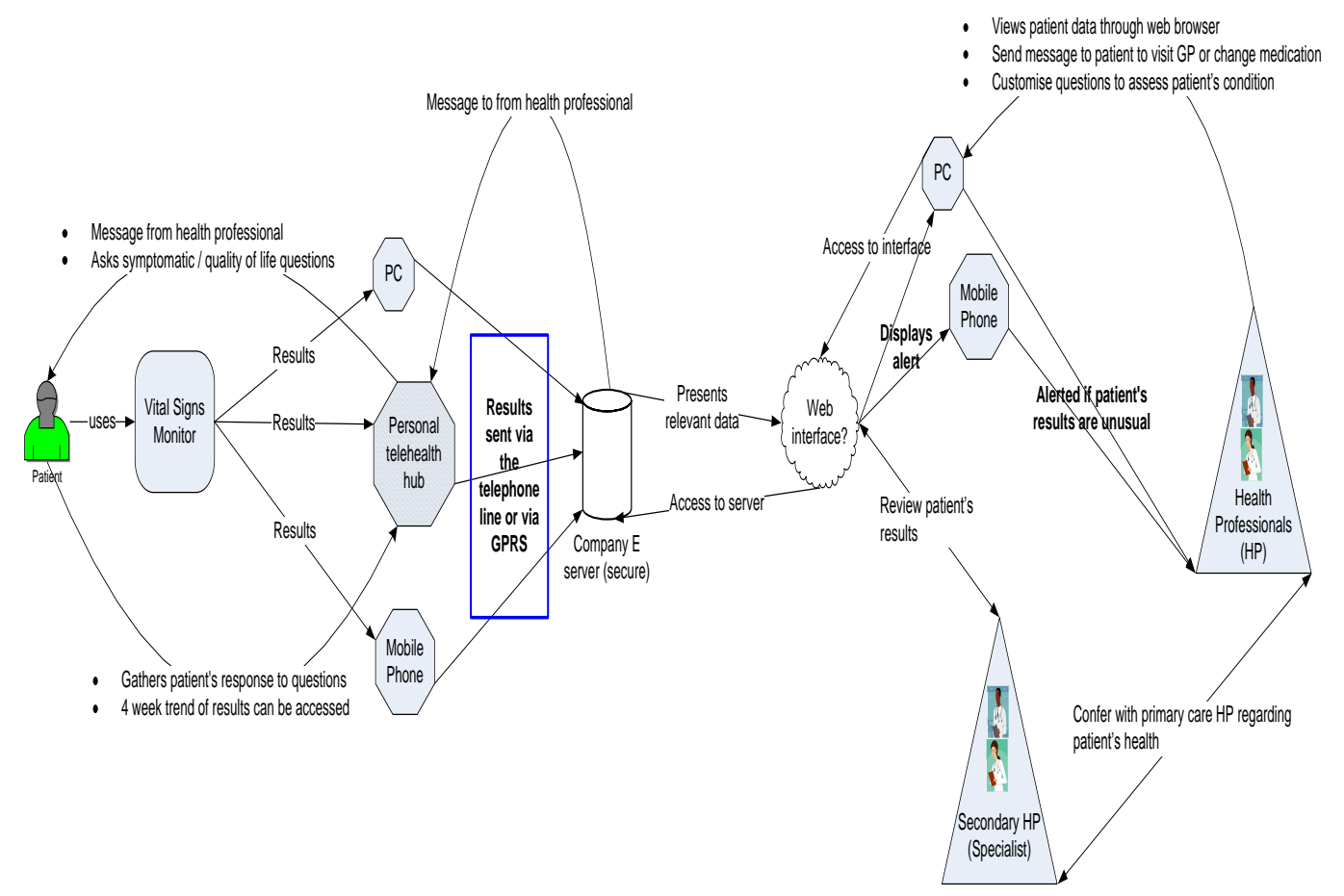

Figure 5 - Offering E representing a telehealth system for managing and preventing long term conditions

\subsection{Offering F}

Offering $F$ (Figure 6) represents a system for monitoring patients with the following chronic conditions: asthma, CHF, COPD, diabetes and hypertension. The system can also monitor patients who have depression, drug and alcohol addiction, are obese, are stopping smoking and have had a stroke. The process begins with the patient using either of five different types of point-of-care devices which included weighing scale, BP monitor, glucometer, peak flow meter and pulse oximeter. Results are sent to a telehealth hub before being sent on to a server. Results are accessible to health professionals in order to assess the patient's health, and compliance with current medication regimes etc. They are also accessible to caregivers. Health professionals can set up alerts to be triggered by unusual results entered by patients. They can also configure the hub with personalised questionnaires. The hub records the patient's response as well as delivering other messages which the health 
professional may have sent. The patient's results are updated on an EPR located at the GP surgery.

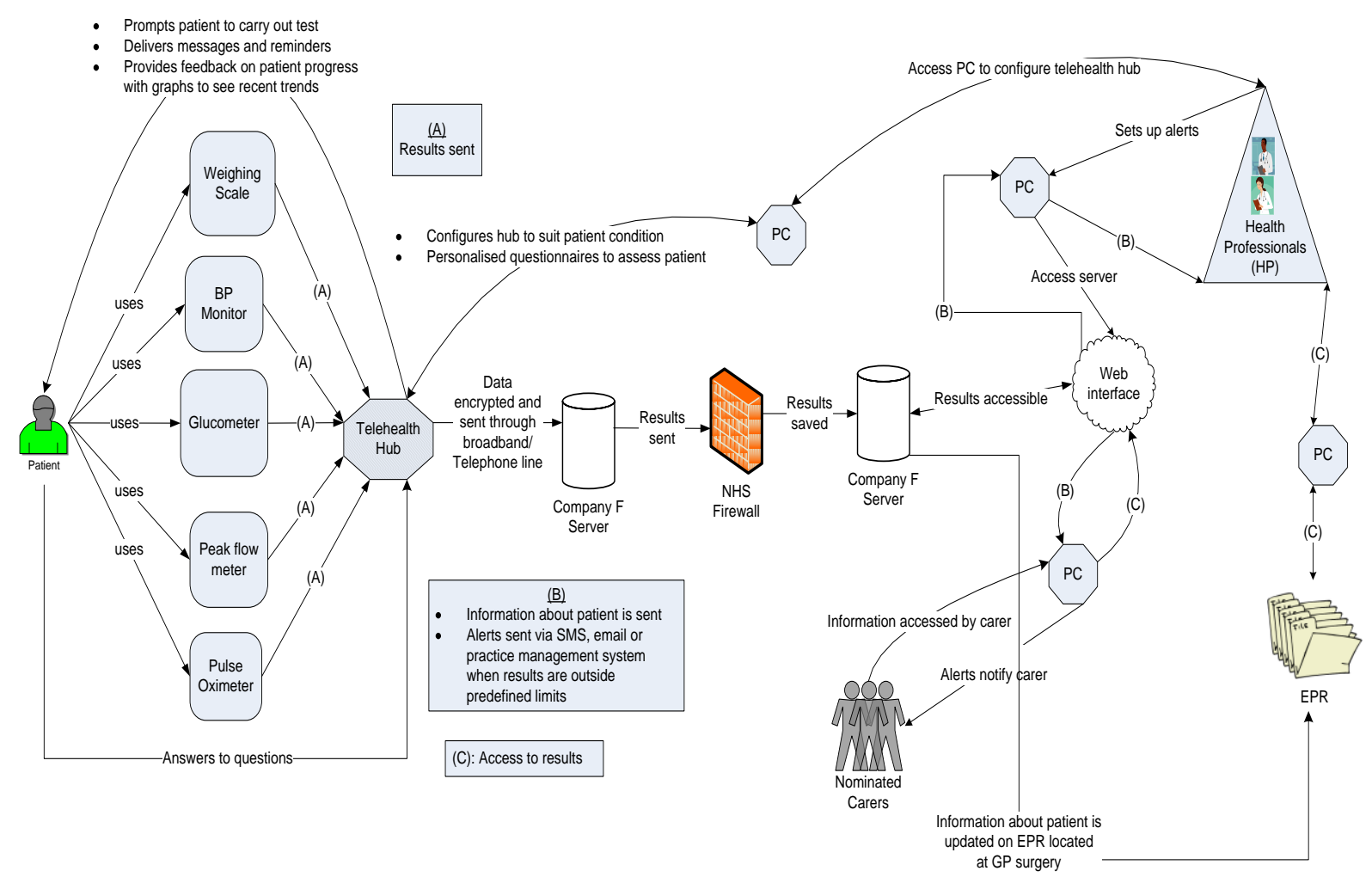

Figure 6 - Offering $\mathrm{F}$ representing a telehealth system for monitoring several chronic conditions

\subsection{Offering G}

Offering G (Figure 7) represents a system for managing several chronic conditions namely chronic heart failure, COPD, diabetes hypertension and stroke.

The process is initiated by the device prompting the patient to perform their test. The patient can use eight different types of point-of-care devices including BP monitor, coagulation meter, glucometer, ECG monitor, peak flow meter, weighing scale, pulse oximeter and temperature probe. The results are sent via a serial port, infrared or Bluetooth to two types of telehealth monitors where type 1 is linked into the system via a telephone 
line and type 2 has GPRS (General Packet Radio Service) capabilities to a GSM network. The telehealth monitors also pose personalised questions to the patient based on their results. These data are transferred automatically to a telehealth software and displayed in a colour coded format thus allowing high priority issues to be quickly identified by health professionals who review and analyse the data to assess the patient's wellbeing. Health professionals are alerted via SMS or email if the patient's results are extreme or if the patient did not send any results.

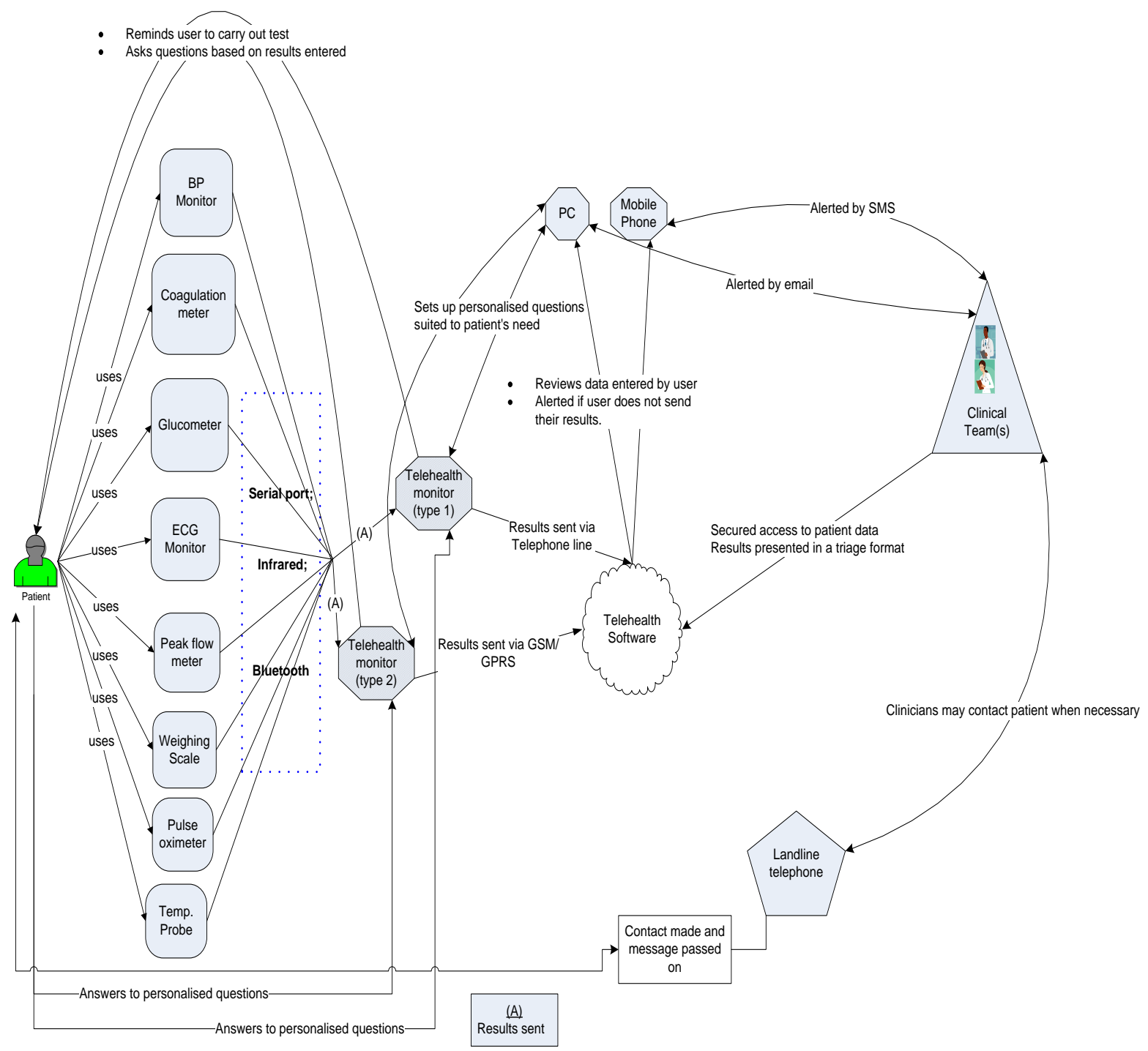

Figure 7 - Offering $\mathrm{G}$ representing a telehealth system for monitoring several chronic conditions 


\subsection{Offering $H$}

Offering $\mathrm{H}$ (Figure 8) represents a system for monitoring several chronic conditions namely COPD, CHF, diabetes and hypertension.

The process is initiated by the device prompting the patient to perform their test. The patient can use six different types of point-of-care devices namely BP monitor, glucometer, pulse oximeter, peak flow meter, weighing scale and ECG monitor. While taking measurements, patients can speak to the health professional on the phone to obtain additional advice and support. Results and responses from questionnaires are sent to the telehealth monitor via a telephone line or via wireless GPRS (if a telephone line was not available). The telehealth monitor has the added advantage that it could be used in a multiuser environment such as a nursing home. Results are encrypted before being stored in two remote databases to increase data security. A web portal is available which provides access to the results. Access to data are provided to health professionals, patients and their caregivers. 


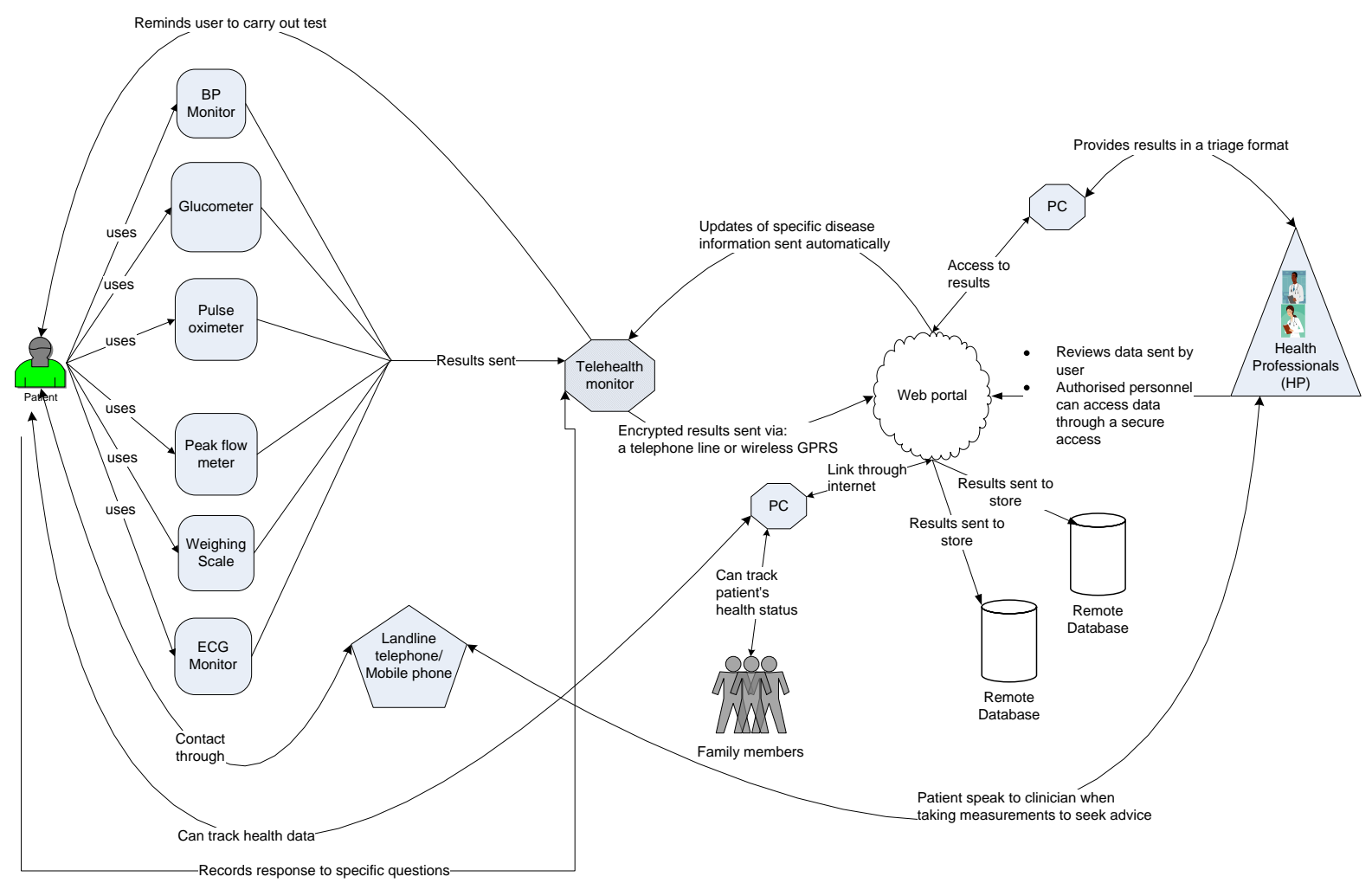

Figure 8 - Offering $\mathrm{H}$ representing a telehealth system for monitoring several chronic conditions

\subsection{Offering I}

Offering I (Figure 9) represents a system for monitoring several chronic conditions namely COPD, chronic heart failure and diabetes.

The process is initiated by the intermediate device prompting the patient to carry out a test known as a 'health session'. During the health session, the patient can watch informative videos about their condition. The patient can use five different types of point-of-care devices which included BP monitor, glucometer, pulse oximeter, peak flow meter and weighing scale. The sessions allow patients to measure vital signs, respond to questions to help assess their health, receive useful information and complete surveys. The intermediate device has audio and video capabilities to enable visual interaction with the health 
professional. Results from the point-of-care devices are sent to the intermediate device initially before they are encrypted and sent to a remote database. At the end of the health session, data are accessed by authorised health professionals from the database via a health care management suite (a web interface). The health care management suite enables health professionals to modify the patient's medication or health routine. It also sends alerts, presented in a triage format, to health professionals when the patient's results are extreme. Health professionals can confer with each other based on information obtained during health sessions. Messages can be sent to the patient via the intermediate device. The intermediate device has the CE mark showing conformation to the EU Medical Device Directive and it also has FDA approval 510(k) [39].

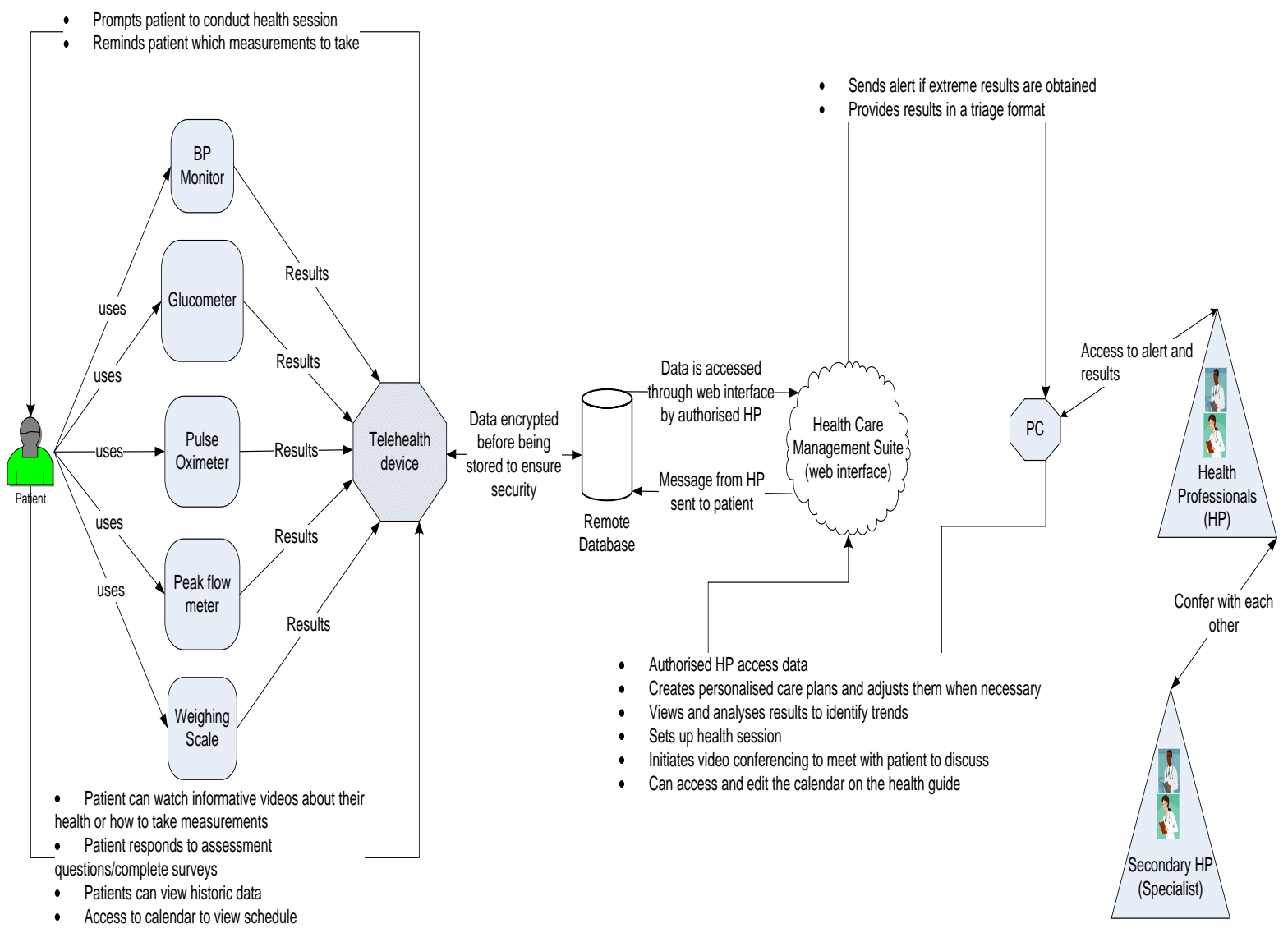

Figure 9 - Offering I representing a telehealth system for monitoring several chronic conditions 


\subsection{Offering J}

Offering J (Figure 10) represents a system for monitoring several chronic conditions.

The process begins with patients or caregivers assisting patients, in using three different types of point-of-care devices which are: weighing scale, BP monitor and pulse oximeter. The results are sent to a telehealth monitor which transmits data to either of the two following intermediate devices. Device A uses an ADSL broadband connection for data transfer while device B can store the data on a removable memory card before using a telephone line to transfer the data to the health care software. Data are downloaded to a PC preinstalled with the software. They are analysed and graphs can be viewed, saved and exported from the software by health care professionals. Access to data is secured through passwords.

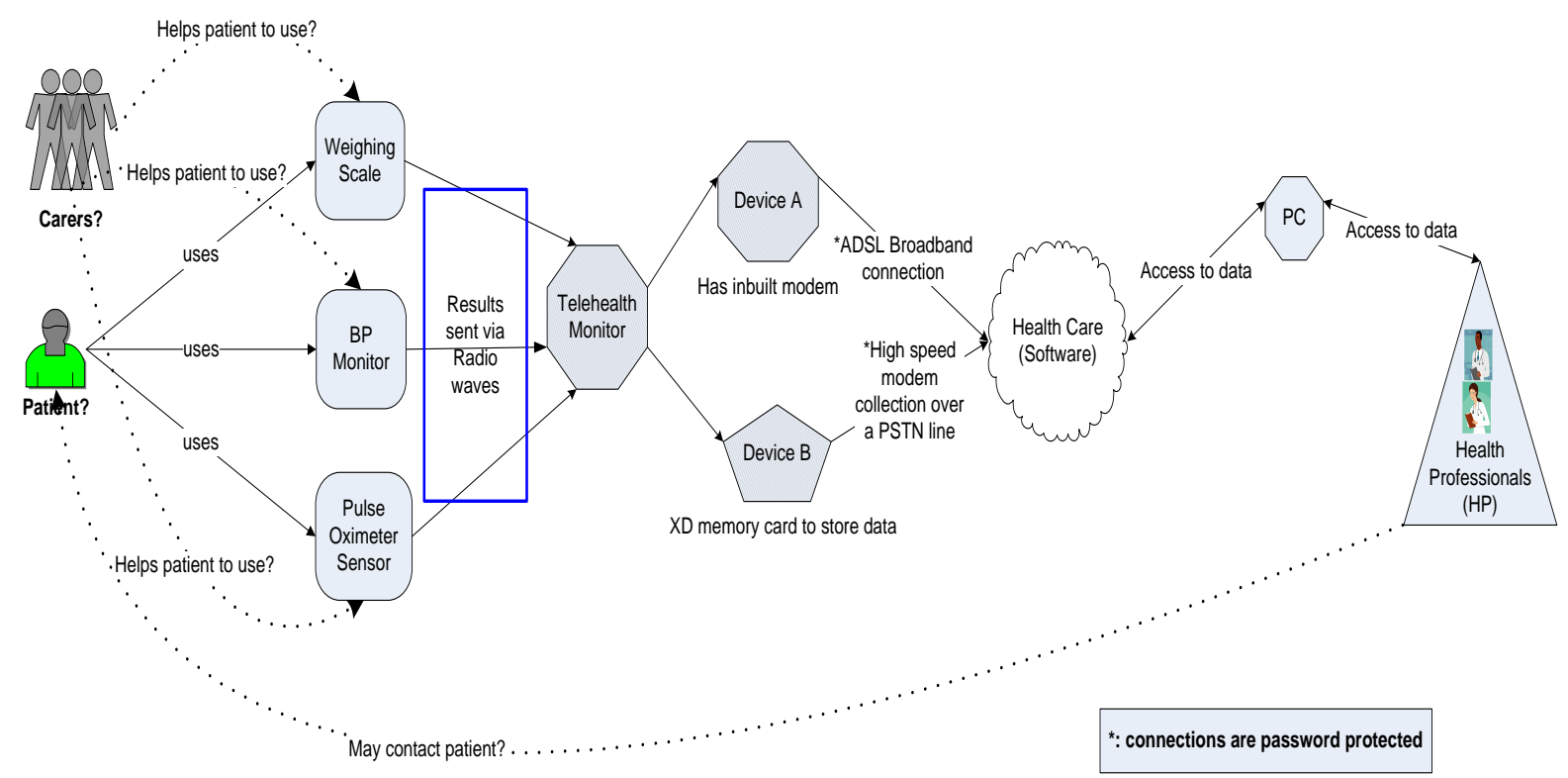

Figure 10 - Offering J representing a telehealth system for monitoring several chronic conditions 


\subsection{Offering $K$}

Offering K (Figure 11) represents a system for managing several chronic conditions.

The process is initiated by the patient who uses five different types of devices, namely weighing scale, BP monitor, glucometer, ECG monitor and pulse oximeter. The results are sent to an intermediate device known as a home hub. Its features include sending reminders to patients to take their medication and providing a questionnaire for patients to complete, based on their condition. Data from the home hub are forwarded on to a remote monitoring station linked to an EPR provided by the organization. The EPR can be configured to deal with different chronic diseases and enables health professionals to set up a specific care plan for patients to monitor their own condition The EPR allows the creation of reports from the data collected and it also alerts the health professional of any unusual results. Caregivers are provided access to patient responses from questionnaires through the home hub. 


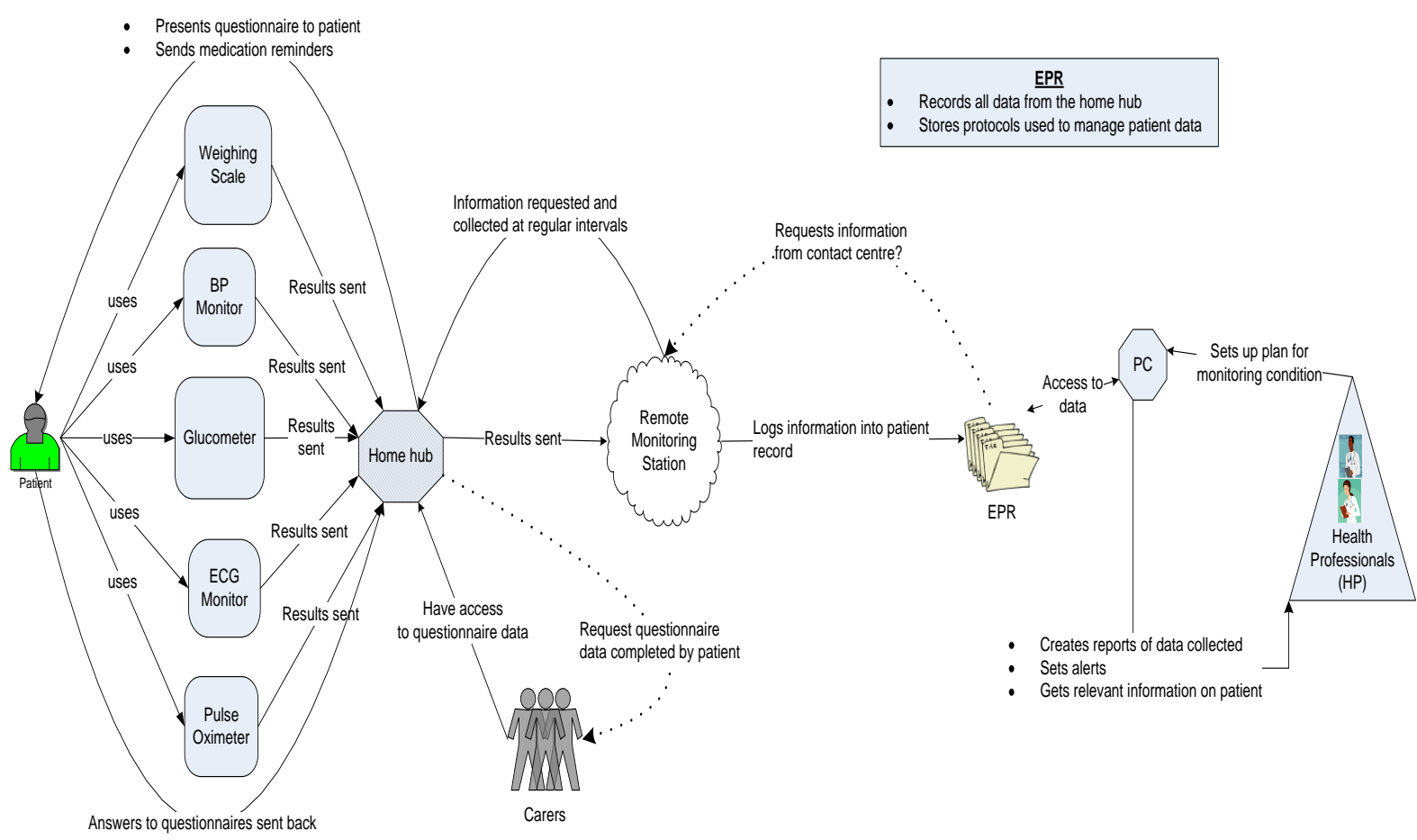

Figure 11 - Offering $\mathrm{K}$ representing a telehealth system for monitoring several chronic conditions

\subsection{Offering $L$}

Offering L (Figure 12) represents a system for monitoring patients with several chronic conditions namely chronic heart failure, diabetes and COPD.

The process begins with the patient using one of the following point-of-care devices: weighing scale, BP monitor, pulse oximeter or glucometer. The results are sent to a set top box wirelessly via Bluetooth for the weighing scale and BP monitor; and via a USB cable for the glucometer. Results from the pulse oximeter and the patient's responses to health assessment questions are manually entered through a TV channel. From the set top box, the results are forwarded via broadband to a secure server. Results are accessible to authorized health professionals via a web interface. In addition to reviewing results, health professionals can create and modify the patient's care plan based on their progress. This 
care plan includes questionnaires which are configured by the health professionals and customized to each patient. Health professionals are alerted when patient's results do not fall within the specified thresholds and a follow-up questionnaire is sent to the patient to confirm their results.

Using the television and a remote control, the patient can access their results, presented in a graphical format, to compare it with targets set by the health professional. They can also watch educational videos and receive messages from their health professional which may include reminders to take their medication.

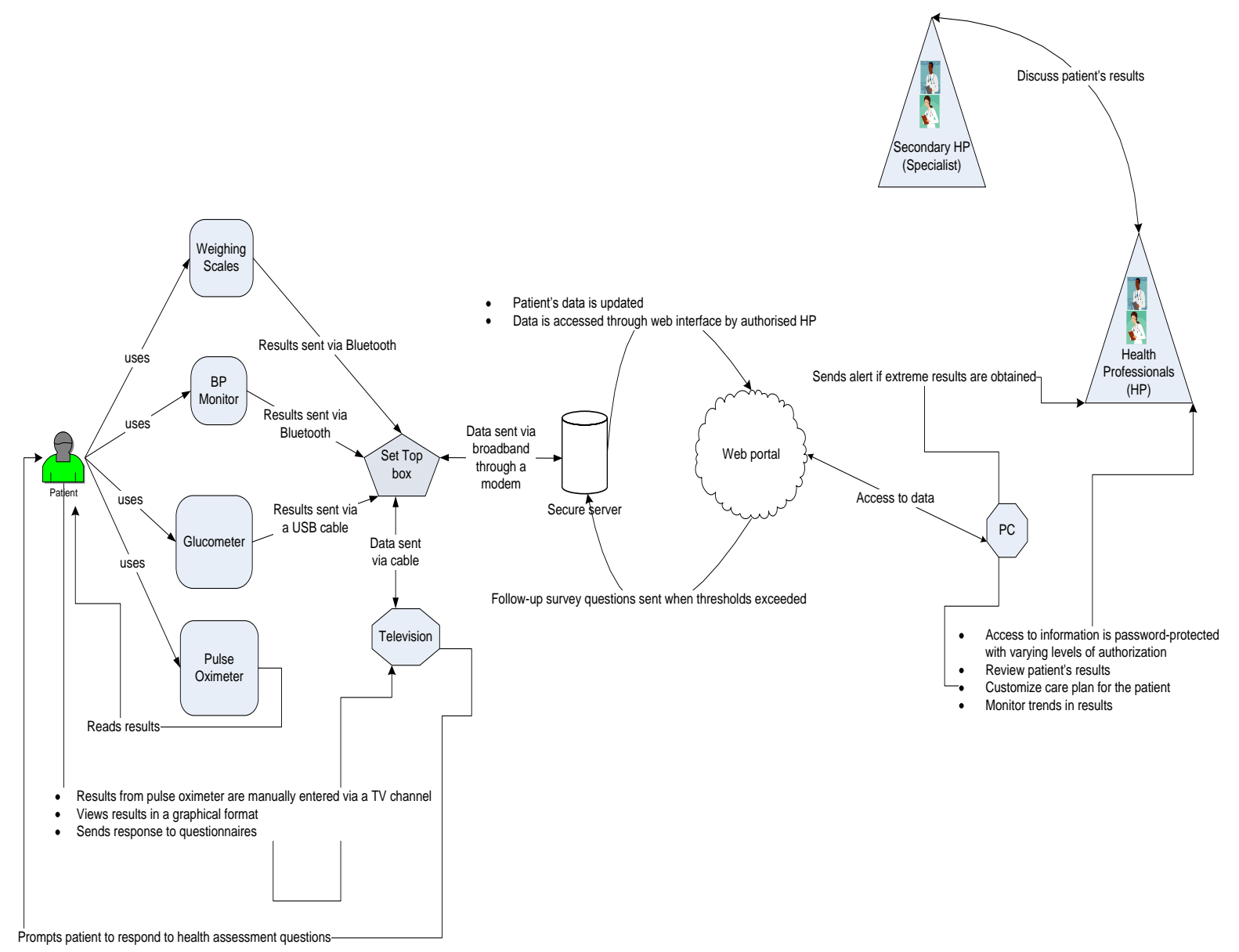

Figure 12 - Offering $L$ representing a telehealth system for monitoring several chronic conditions 


\section{Figure Legends}

Figure 1 - Offering A representing a telehealth system for diabetes management

Figure 2 - Offering B representing a telehealth system for monitoring several chronic conditions

Figure 3 - Offering $\mathrm{C}$ representing a telehealth system for monitoring several chronic conditions

Figure 4 - Offering D representing a telehealth system for monitoring cardiac and respiratory conditions

Figure 5 - Offering E representing a telehealth system for managing and preventing long term conditions

Figure 6 - Offering $\mathrm{F}$ representing a telehealth system for monitoring several chronic conditions

Figure 7 - Offering $\mathrm{G}$ representing a telehealth system for monitoring several chronic conditions

Figure 8 - Offering $\mathrm{H}$ representing a telehealth system for monitoring several chronic conditions

Figure 9 - Offering I representing a telehealth system for monitoring several chronic conditions

Figure 10 - Offering J representing a telehealth system for monitoring several chronic conditions

Figure 11 - Offering $\mathrm{K}$ representing a telehealth system for monitoring several chronic conditions

Figure 12 - Offering $L$ representing a telehealth system for monitoring several chronic conditions 